\title{
User's Guide to the Yucca Mountain Integrating Model (YMIM) \\ Version 2.1
}
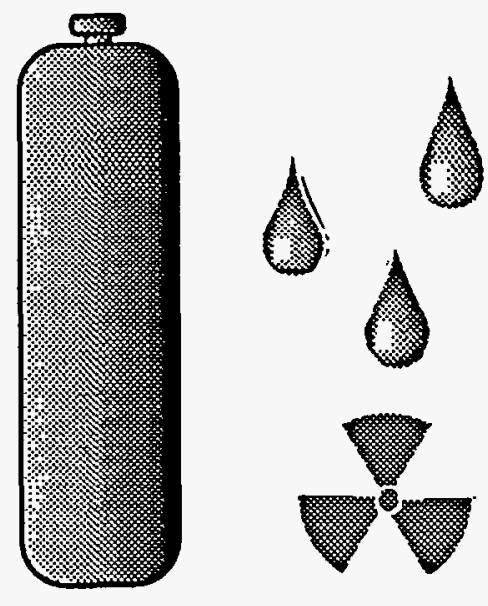

By:

J. Gansemer and

A. Lamont 


\section{DISCLAIMER}

This report was prepared as an account of work sponsored by an agency of the United States Government. Neither the United States Government nor any agency thereof, nor any of their employees, make any warranty, express or implied, or assumes any legal liability or responsibility for the accuracy, completeness, or usefulness of any information, apparatus, product, or process disclosed, or represents that its use would not infringe privately owned rights. Reference herein to any specific commercial product, process, or service by trade name, trademark, manufacturer, or otherwise does not necessarily constitute or imply its endorsement, recommendation, or favoring by the United States Government or any agency thereof. The views and opinions of authors expressed herein do not necessarily state or reflect those of the United States Government or any agency thereof. 


\section{DISCLAIMER}

Portions of this document may be illegible in electronic image products. Images are produced from the best available original document. 


\section{Contents}

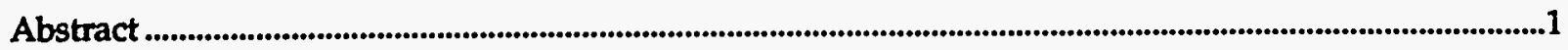

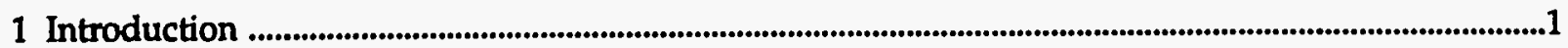

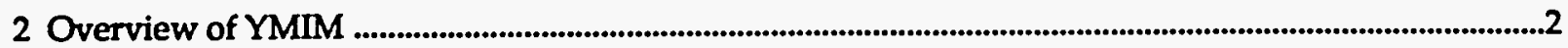

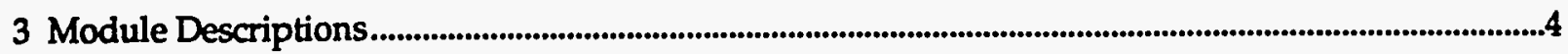

3.1 Time Points Module ....................................................................................................................................4

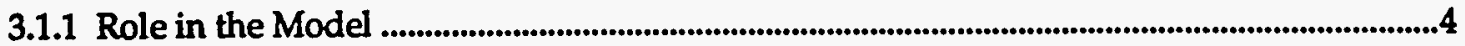

3.1.2 Internal Modeling and Assumptions ................................................................................................4.4

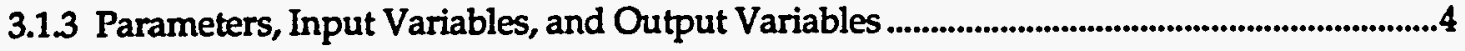

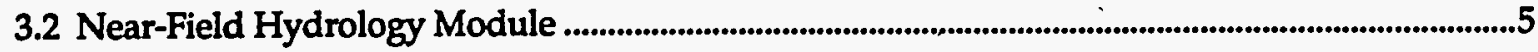

3.2.1 Role in the Model ................................................................................................................................5

3.2.2 Internal Modeling and Assumptions ...................................................................................................5

3.2.3 Parameters, Input Variables, and Output Variables .......................................................................5

3.3 Near-Field Chemistry Module ...................................................................................................................6

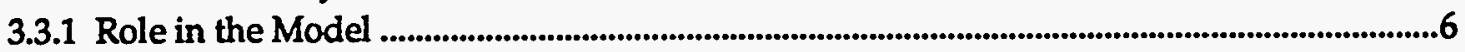

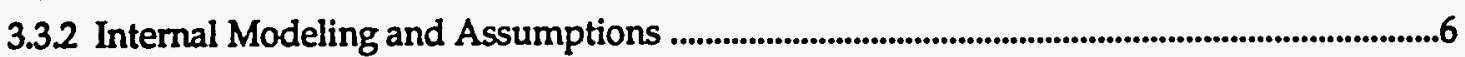

3.3.3 Parameters, Input Variables, and Output Variables ..................................................................6

3.4 Rock-to-Container Flow Module ..........................................................................................................6

3.4.1 Role in the Model .................................................................................................................................6

3.4.2 Internal Modeling and Assumptions ............................................................................................7

3.4.3 Parameters, Input Variables, and Output Variables ..................................................................7

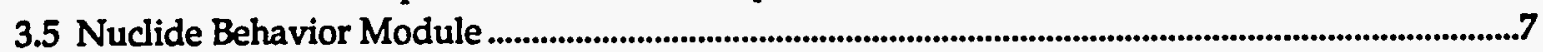

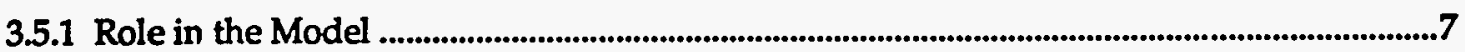

3.5.2 Internal Modeling and Assumptions ...............................................................................................7

3.5.3 Parameters, Input Variables, and Output Variables ...................................................................8

3.6 Fuel Rod and Container Temperature Module ................................................................................................8

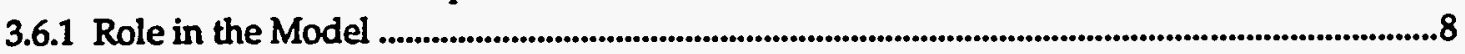

3.6.2 Internal Modeling and Assumptions ..................................................................................................8

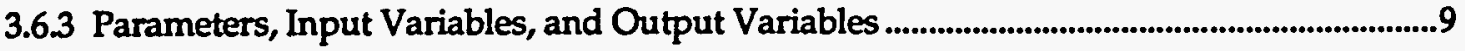

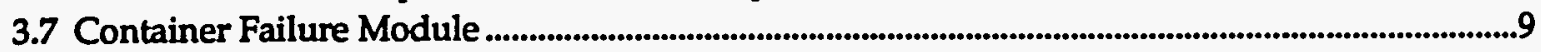

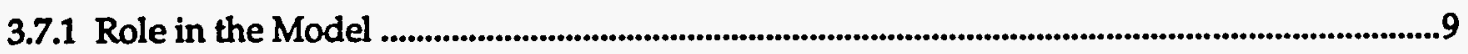

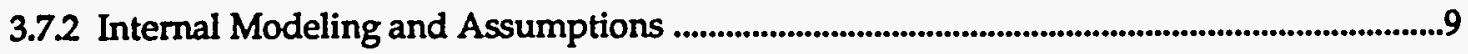

3.7.2.1 Dry Oxidation Corrosion Model ............................................................................................. 9

3.7.2.2 General Wet Oxidation Corrosion Model ...........................................................................9

3.7.2.3 General Wet Oxidation Corrosion Model with a Pitting Factor ..............................10

3.7.2.4 Probabilistic Aqueous Pitting Corrosion Model........................................................... 10

3.7.2.5 Failures Due to Defects and Unspecified Causes ............................................................... 17

3.7.3 Parameters, Input Variables, and Output Variables .....................................................................17

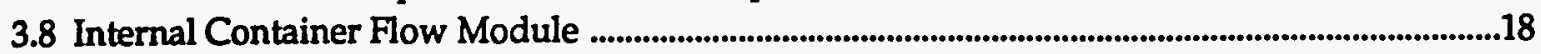

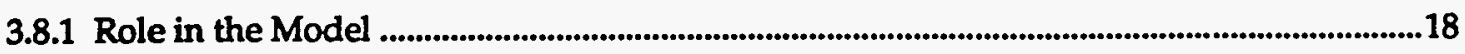

3.8.2 Internal Modeling and Assumptions .......................................................................................18

3.8.3 Parameters, Input Variables, and Output Variables .................................................................19

3.9 Cladding Failure Module....................................................................................................................19 


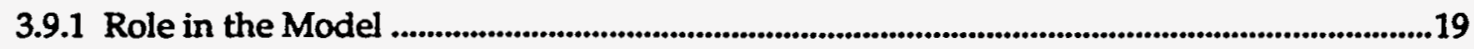

3.9.2 Internal Modeling and Assumptions ..............................................................................................19

3.9.3 Parameters, Input Variables, and Output Variables ............................................................21

3.10 Dissolution and Accounting Module ....................................................................................................21

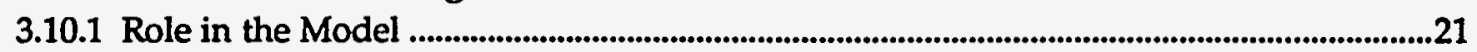

3.10.2 Internal Modeling and Assumptions ...................................................................................21

3.10.2.1 Internal Structure of the Dissolution and Accounting Module..............................21

3.10.2.2 Outline of the Calculation Steps for Each Period ........................................................2 23

3.10.2.3 Calculation of Container and Cladding Failures ..........................................................23

3.10.2.4 Calculation of Waste-Form Oxidation and Alteration ................................................24

3.10.2.5 Nuclide Release Processes......................................................................................................25

3.10.2.6 Nuclide Decay.......................................................................................................................26

3.10.3 Parameters, Input Variables, and Output Variables ...............................................................26

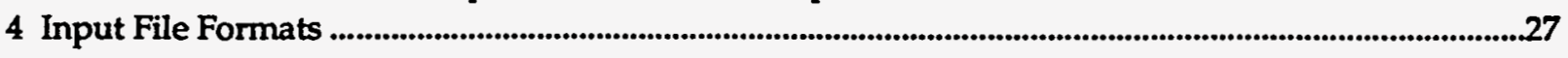

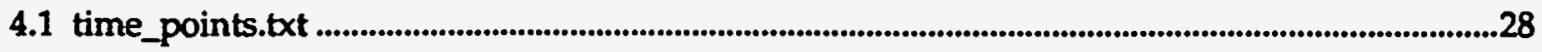

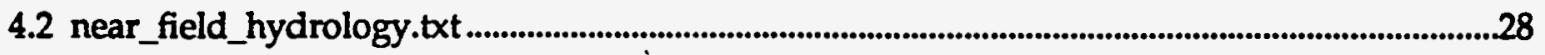

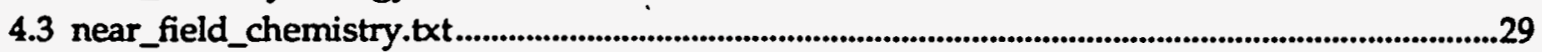

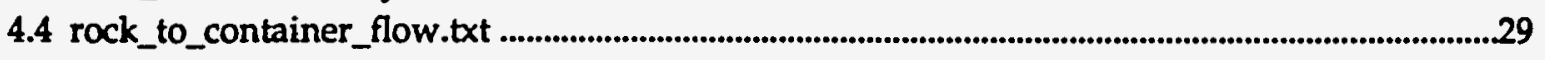

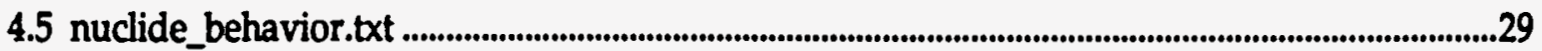

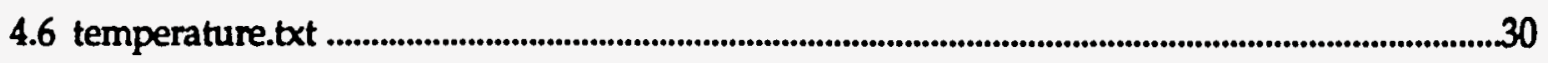

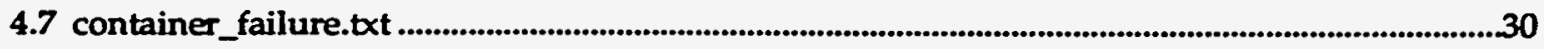

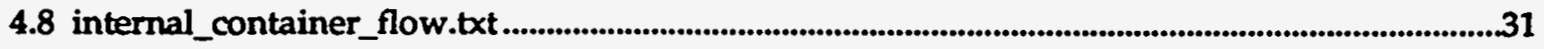

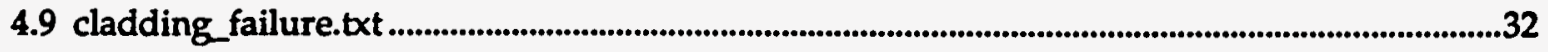

4.10 dissolution_and_accounting,txt ................................................................................................................32

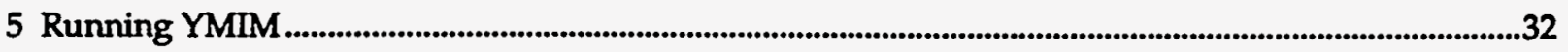

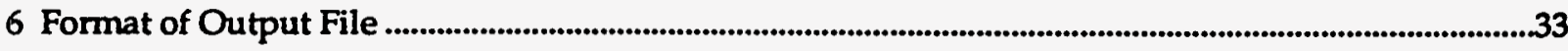

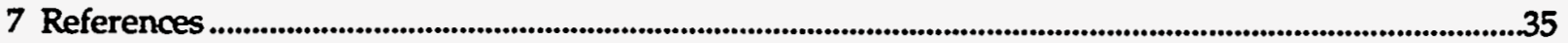




\title{
User's Guide to the Yucca Mountain Integrating Model (YMIM), Version 2.1
}

\begin{abstract}
The Yucca Mountain Integrating Model (YMIM) is an integrated model of the engineered barrier system. It contains models of the processes of waste container failure and nuclide release from the fuel rods. YMIM is driven by scenarios of container and rod temperature, near-field chemistry, and near-field hydrology provided by other modules. It is designed to be highly modular so that a model of an individual process can be easily modified or replaced without interfering with the models of other processes. This manual describes the process models and provides instructions for setting up and running YMIM Version 2.1.
\end{abstract}

\section{Introduction}

The release of nuclides from the waste containers in the potential Yucca Mountain nuclear waste repository will be determined by the near-field hydrologic, thermal, and chemical processes and the repository's engineered barrier systems. Evaluating the overall releases requires the integration of models of each of these components. The Yucca Mountain Integrating Model (YMIM) is a modular framework for integrating these models to estimate nuclide releases over time.

Each module in YMIM contains a model of one of the processes in the mobilization and release of nuclides from the repository. Because the modules have standardized inputs and outputs, a user can easily modify the behavior of a module without altering related modules and use YMIM to evaluate the impact of that behavior on long-term releases. Through this structure, YMIM provides a test bed for exploring the impact of different scenarios or assumptions about processes, taking into account the interactions among all of the processes and scenarios that occur in the near-field.

The current modules take into account the flow of water onto the containers, corrosion of the containers, failure of the fuel rod cladding, dissolution of the fuel matrix, and the flow of water out of the containers. YMIM Version 2.1 contains modules that model:

- Near-field hydrology.

- Near-field chemistry.

- Fuel rod and container temperature.

- Rock-to-container flow.

- Container failure.

- Internal container flow.

- Nuclide behavior.

- Cladding failures.

- Waste Form dissolution and accounting.

This report describes the components of YMIM in detail and the instructions for running it. Section 2 provides an overview of the way that YMIM models nuclide releases from the repository. Section 3 
describes each of the modules, outlining their inputs and outputs and describing their internal models. Section 4 describes the input files and their formats. The final sections give instructions for running YMIM Version 2.1 and the format of the outputs.

\section{Overview of YMIM}

YMM was developed to model the release history of nuclides from a group of containers under scenarios of near-field conditions (temperature, hydrology, and chemistry). It is assumed that all of the containers in the group are subjected to the same near-field conditions of temperature, hydrology, and chemistry. Of course, these conditions are expected to vary from one part of the repository to another. To estimate releases across the entire repository, several YMIM runs would be required, each one modeling the conditions at a different location.

The scenarios that drive a YMIM run describe the temperature, hydrology, and near-field chemistry conditions existing during a series of periods (which do not necessarily have equal lengths). Because these scenarios are input to YMIM and are not internally constructed, it is essential that the user prepare sets of scenarios that are consistent. Normally the preparation of these scenarios is based on other models of the behavior of near-field conditions.

Although a number of modules are used in YMIM, most of the modeling occurs in four: Container Failure, Cladding Failure, Internal Container Flow, and Dissolution and Accounting. The remaining modules provide data on the scenario being analyzed or incorporate very simple calculations. These four principal modules use the following modeling approaches:

Container Failure. This module can model the corrosion of single- and double-walled containers. It can model dry oxidation, general aqueous corrosion, and pitting corrosion. For each wall, the user specifies the mode of corrosion. When pitting corrosion is specified, a stochastic model of pit growth is used, which leads to a probability distribution over the time at which containers fail.

Cladding Failure. The fuel rod cladding in the container can fail because of high-temperature creep, hydride reorientation, or the presence of fluorine in the groundwater. The Cladding Failure module uses simple models to estimate the rate at which these types of failures occur at each period in the scenario.

Internal Container Flow. This module estimates the total exposed area of the waste for.n in a container, the portion of that area that is wetted, and the rate of water flow over the exposed areas of the waste form once the container fails.

Dissolution and Accounting. This module models the process of dissolution of the fuel matrix and accounts for the mass of each nuclide that is released. The dissolution estimate is based on an alteration model-materials cannot be released from the container at a rate greater than the rate at which the fuel matrix is altered by either dry oxidation or aqueous alteration. The release of a given nuclide also cannot exceed its solubility in the water that is flowing over the exposed fuel matrix in the container. This module keeps track of the total dissolution in containers to ensure that the dissolution does not exceed the amount of material that is actually exposed to the dissolution process.

Figure 2-1 shows a schematic of the modules and the information passed between them. The next section describes the information available from each module and gives detailed process descriptions.

For each period, YMIM models the additional container and cladding failures and the additional dissolution of material from containers that have failed and are in contact with water. It then computes the rate of release of each nuclide tracked during the period.

Because YMIM is structured around modules and these modules exchange information, it is natural to implement it using an object-oriented language. $\mathrm{C}++$ was selected because it has all of the features that were needed for YMIM and is available on a wide variety of machines. YMIM is currently implemented on both the Apple Macintosh and the Sun workstation. 


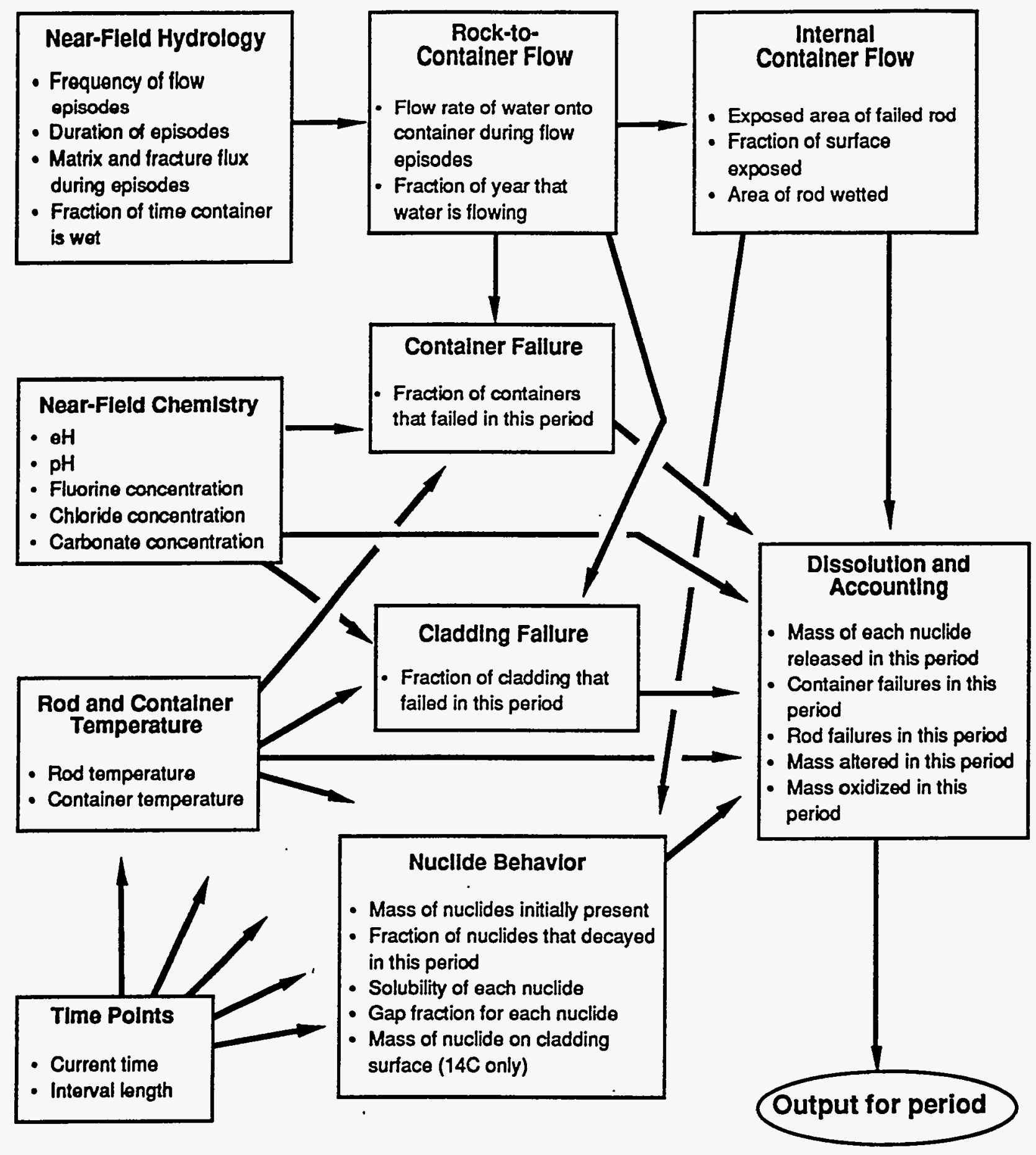

Figure 2-1. Diagram of the modules in YMIM Version 21. Each module contains a model of a process and can provide information to other modules. The items in each block show the information that the module can provide. Arrows show the information flow. 
The computer program consists of a main driving routine and the set of modules, which are implemented as objects. * When a run of YMIM is started, the main driving routine is executed first. It creates the objects for each of the modules and instructs them to initialize themselves. During initialization, a module reads its data from its own data file and makes any initial computations and variable assignments it needs.

After initialization, the main driving routine steps through the periods of the run. Each period, it instructs the Dissolution and Accounting module to compute the releases for that period. To perform this computation, the Dissolution and Accounting module updates its internal state and calculates the releases. Doing so, however, requires information from several other modules. The Dissolution and Accounting module passes messages requesting the needed information to the modules that can supply it. When they receive this request, the modules update their internal state for that period and request whatever information they need from still other modules. This chain of calls continues until the modules that simply provide scenarios are reached. These return the values needed, and each module along the chain can then complete its calculation.

\section{Module Descriptions}

This section describes the role of each of the modules in YMIM Version 2.1, giving an overview of its relationship to other modules. It also describes the internal modeling used in the current version of the module and lists the input variables, parameters, and outputs.

\subsection{Time Points Module}

\subsubsection{Role in the Model}

The Time Points module provides information about the periods for which releases are calculated. Releases are calculated for the end of each of the periods defined by this module. At any step in the model run, this module will return the time at the end of the current period and the duration of the current period. Several other modules need this informativa to complete their calculations.

Note that this module only describes the time points at which releases are to be calculated. The input scenarios for temperature, hydrology, and near-field chemistry are also described as a series of periods and the conditions prevailing in each period. However, the periods defined for these input scenarios do not necessarily correspond to the periods defined in the Time Points module. If needed, the other modules will interpolate from their input scenarios to find appropriate values for their variables at each of the periods defined in this module.

\subsubsection{Internal Modeling and Assumptions}

Time Points reads a data file that contains a series of points which are end points of the intervals to be calculated.

\subsubsection{Parameters, Input Variables, and Output Variables}

Input Parameters

- End time for each period (yr).

Input Variables from Other Modules

- None.

\footnotetext{
- In an object-ortented language, an "object" is a module of the program that includes its own data and a set of subroutines that cen operate on the date One object can call another and instruct it to execute one of its routines. The routine might cause the object to initialize itself by reading data from a file, or it might instruct the called object to compute an answer and pass it back to the calling object.
} 


\section{Output Variables}

- Present time (yr).

- Interval length (yr).

\subsection{Near-Field Hydrology Module}

\subsubsection{Role in the Model}

The Near-Field Hydrology module provides the information about the flux of water in the rock at the repository horizon. This information is used by the Rock-to-Container Flow module to estimate the flow of water onto a container.

\subsubsection{Internal Modeling and Assumptions}

The current module reads the flux data for each period from a data file. Part of the flux at the repository horizon moves through rock fractures and part through the rock matrix. These two fluxes are specified independently. Because the corrosion model requires information about the fraction of the year that the waste package is wet, while waste form dissolution requires information about the volume of water encountering exposed waste form, Near-Field Hydrology needs to provide the fraction of the year that the container is wet as well as the flow rate. In addition, because there may be periods when the rock is wet but there is no flux, the portion of the time that the rock is wet is specified independently of the matrix and fracture fluxes.

The flux and wetting are assumed to occur in episodes, which might have a frequency ranging from months to years. Typically, the frequency will be considerably smaller than the length of a period. For each period, the data describes the magnitude of the fluxes, the frequency of flow episodes, and the duration of episodes. The fracture flux and matrix flux can have different frequencies and durations. The data also describe the frequency and duration of periods of wetting.

All of these parameters are specified by the user and are independent. Therefore, it is up to the user to ensure that they are specified consistently. In addition, because the flux at the repository is determined by the thermal history of the repository, the user must ensure that the scenario of flux input to this module is consistent with the temperature scenario input to the Temperature module. The periods specified in defining the scenarios do not have to be the same as the periods used in the Time Points module, although it is recommended that the evaluation points used by the Time Points module include all times at which temperature, hydrology, and chemistry conditions change. If they do not correspond, the module interpolates to the appropriate values for the current time. Since the model interpolates between values, two time points with a small $\Delta t$ should be used to simulate a step increase in parameters.

\subsubsection{Parameters, Input Variables, and Output Variables}

\section{Input Parameters}

- Time points at which flux conditions change, including time zero (yr).

- Matrix and fracture flux levels during flow episodes at time zero and at the points at which flux conditions change (mm/yr).

- Durations of matrix and fracture flow episodes at time zero and for each period (fraction of year).

- Number of matrix and fracture flow episodes occurring per year at time zero and for each period (\#/yr).

- Number of wetting episodes per year at time zero and for each period (\#/yr).

- Duration of wetting episodes at time zero and for each period (fraction of year).

Input Variables from Other Modules

- None.

Output variables

- Level of matrix flux during episodes $(\mathrm{mm} / \mathrm{yr})$.

- Level of fracture flux during episodes $(\mathrm{mm} / \mathrm{yr})$. 
- Number of matrix-flux episodes per year.

- Number of fracture-flux episodes per year.

- Number of container-wetting episodes per year.

- Duration of matrix-flux episodes (fraction of year).

- Duration of fracture-flux episodes (fraction of year).

- Duration of container-wetting episodes (fraction of year).

\subsection{Near-Field Chemistry Module}

\subsubsection{Role in the Model}

The Near-Field Chemistry module provides information about the chemistry of the water at the repository horizon. This information currently includes $\mathrm{pH}, \mathrm{eH}$, chloride concentration, carbonate concentration, and fluorine concentration. In the current version, this information is used to estimate the rate of container corrosion, cladding failure rates due to fluorine, and the alteration rate of the fuel matrix.

\subsubsection{Internal Modeling and Assumptions}

Near-Field Chemistry currently reads a data file that contains a time history scenario of near-field chemistry at the repository. At the request of other modules, it will return any of the chemistry variables for the current period.

The time periods at which chemistry values are specified need not correspond to the time periods specified in the Time Points module. If they do not correspond, the module interpolates to the appropriate values for the current time.

\subsubsection{Parameters, Input Variables, and Output Variables}

Input Parameters

- Time points at which chemistry conditions change (beginning with time zero) (yr).

- $\mathrm{pH}$ at time zero and at the end of each period.

- $\mathrm{eH}$ at time zero and at the end of each period.

- Fluorine concentration at time zero and at the end of each period (ppm).

- Criboride concentration at time zero and at the end of each period (ppm).

- Carbonate concentration at time zero and at the end of each period (moles/liter).

(Note that although eH must be input in the file, it is not presently used in the calculations.)

Input Variables from Other Modules

- Time at the end of the current period (yr) from Time Points.

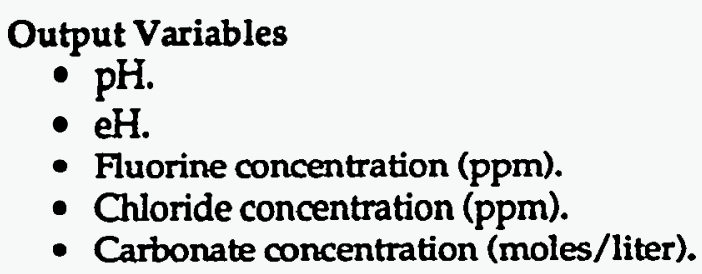

\subsection{Rock-to-Container Flow Module}

\subsubsection{Role in the Model}

The Rock-to-Container Flow module models the flow of water from the rock wall of the drift or borehole to the container. This module provides the fraction of the year that the container is wet for the Container Failure module (corrosion) and the volume of water entering a breached container per year for the Internal Container Flow module. The fluxes at the rock wall are given by the Near-Field Hydrology module. The current implementation of the module essentially assumes an air gap between the rock and the container that does not impede the flow of water from the rock to the container. However, future 
versions of this module can be used to model the case in which there is packing or backfill between the rock and the container.

\subsubsection{Internal Modeling and Assumptions}

The current implementation of this module assumes that there is a "collection area" for each container. The size of the area is input by the user. The amount of flux through this area is the amount of flux that reaches the container. A vertically placed container, for example, might have a collection area roughly the size of the container's horizontal cross-sectional area if it is assumed that there is no concentration of flux and no dispersal of flux away from the container. For example, a fracture flux of $1.0 \mathrm{~mm} / \mathrm{yr}$ passing through a collection area of $1.0 \mathrm{~m}^{2}$ would result in a flow rate of $1 \mathrm{liter} / \mathrm{yr}$ onto the container. The model allows the user to define different areas for matrix flow and for fracture flow. The total flow reaching the container is the sum of the two flows.

The module also passes along the information about the fraction of the year that the containers are wet from the Near-Field Hydrology module to the Container Failure module.

\subsubsection{Parameters, Input Variables, and Output Variables}

Input Parameters

- Matrix collection area $\left(\mathrm{m}^{2}\right)$.

- Fracture collection area $\left(\mathrm{m}^{2}\right)$.

Input Variables from Other Modules

- Matrix and fracture flux levels during flows (mm/yr) from Near-Field Hydrology.

- Duration of matrix and fracture flows (yr) from Near-Field Hydrology.

- Number of matrix and fracture flows occurring per year (\#/yr) from Near-Field Hydrology.

- Frequency of wetting episodes (\#/yr) from Near-Field Hydrology.

- Duration of wetting episodes (yr) from Near-Field Hydrology.

- Time at end of current period (yr) from Time Points.

\section{Output Variables}

- Annual volume of water reaching container (liters/yr).

- Fraction of year that the container is wet.

\subsection{Nuclide Behavior Module}

\subsubsection{Role in the Model}

The Nuclide Behavior module supplies information about the nuclides to other modules and computes the amount of decay during the current period. The information that it supplies includes the amount of each nuclide in a single fuel rod, the fraction that has decayed up to the current period, form of the nuclide (solid or gas), the amount of the nuclide in the gap between the fuel pellet and the cladding, and the amount of the nuclide on the surface of the cladding that will be released upon container failure (applies oniy to ${ }^{14} \mathrm{C}$ ). This information is used by Dissolution and Accounting to determine nuclide release during each time period.

\subsubsection{Internal Modeling and Assumptions}

The solubility of each nuclide depends on the current temperature of the fuel matrix. In the current version, the user inputs the solubility at two different temperatures. The module makes a linear interpolation or extrapolation to find the solubility at any other temperature.

A small fraction of each nuclide can migrate to the gap between the fuel pellets and the cladding. In the case of highly soluble nuclides and ${ }^{14} \mathrm{C}$, this gap material will be released even without alteration of the fuel matrix. The user specifies the fraction of the nuclide that is in the gap. The module then calculates the total mass of the nuclide in the gap for a single rod using the total mass of the nuclide in a rod.

Gaseous nuclides such as ${ }^{14} \mathrm{C}$ are also modeled here. For each nuclide, the user specifies whether it is present in solid form or gaseous form. This specification allows the Dissolution and Accounting module 
to use the correct models in calculating releases. In this version, it is assumed that there is an amount of ${ }^{14} \mathrm{C}$ on the surface of the cladding due to neutron reactions on ${ }^{14} \mathrm{~N},{ }^{17} \mathrm{O}$, and ${ }^{13} \mathrm{C}$. The user specifies the amount of ${ }^{14} \mathrm{C}$ per unit area that is to be released from the surface. The module computes the total mass present. The remainder of the releases are calculated by the Dissolution and Accounting module in a similar fashion to the calculation of the other nuclides.

The module also calculates the decay of each nuclide. However, the current module is based only on the half-life of the nuclide and does not account for daughter products of decay. At each period, the module computes the fraction of each nuclide that has decayed.

\subsubsection{Parameters, Input Variables, and Output Variables}

Input Parameters

- Names of nuclides present ( 4 or 5 character names required).

- Mass of each nuclide contained in a single fuel rod (g).

- Half-life of each nuclide (yr).

- Form of the nuclide ( $\mathrm{S}=$ solid, $\mathrm{G}=$ gas).

- Temperatures at which solubilities are specified. Two temperatures (Temperature 1 and Temperature 2) are input and used for all nuclides $\left({ }^{\circ} \mathrm{C}\right)$.

- Solubility limit of each nuclide at Temperature 1 (g/liter).

- Solubility limit of each nuclide at Temperature $2(\mathrm{~g} / \mathrm{liter})$.

- Fraction of the mass of each nuclide at the waste-form boundary (gap fraction) (decimal fraction).

- Amount of nuclide on the cladding surface of a single fuel rod that will be released upon container failure (applies only to gaseous nuclides such as $\left.{ }^{14} \mathrm{C}\right)\left(\mathrm{g} / \mathrm{m}^{2}\right)$.

- Total mass of all nuclides in a single fuel rod (g).

Input Variables from Other Modules

- Length of the current time period (yr) from Time Points.

- Cross-sectional area of a fuel pellet from Internal Container Flow.

- Length of a fuel rod from Internal Container Flow.

- Time at the end of the current period (yr) from Time Points.

\section{Output Variables}

- Names of nuclides.

- Fraction of each nuclide that decayed during the period.

- Solubility limit of each nuclide during the current period ( $\mathrm{g} / \mathrm{liter}$ ).

- Fraction of mass of each nuclide at the waste-form surface (gap fraction).

- Mass of each nuclide in a single fuel rod (g).

- Mass of ${ }^{14} \mathrm{C}$ on the cladding surface of a single fuel $\operatorname{rod}\left(\mathrm{g} / \mathrm{m}^{2}\right)$.

\subsection{Fuel Rod and Container Temperature Module}

\subsubsection{Role in the Model}

The Fuel Rod and Container Temperature module provides the temperatures at the container wall and at the rods. This information is used to calculate the container corrosion rates in the Container Failure module, the fuel matrix alteration rate in the Dissolution and Accounting module, the solubilities in the Nuclide Behavior module, and the cladding failures in the Cladding Failure module.

\subsubsection{Internal Modeling and Assumptions}

The module computes the rod and container wall temperatures during the current time interval. It reads a data file that contains the time history scenario of temperature at the surface of the fuel rods and at the container wall. The time periods at which temperatures are specified need not correspond to the time periods specified in the Time Points module. If they do not correspond, the Rod and Container Temperature module interpolates to the appropriate temperature for the current time. 


\subsubsection{Parameters, Input Variables, and Output Variables}

Input Parameters

- Time points at which temperature conditions change, including time zero (yr).

- Temperature at the cladding surface at time zero and at the end of each period $\left({ }^{\circ} \mathrm{C}\right)$.

- Temperature at the container wall at time zero and at the end of each period $\left({ }^{\circ} \mathrm{C}\right)$.

Input Variables from Other Modules

- End time of the current time period (yr) from Time Points.

Output Variables

- Temperature at the cladding surface $\left({ }^{\circ} \mathrm{C}\right)$.

- Temperature at the container wall surface $\left({ }^{\circ} \mathrm{C}\right)$.

\subsection{Container Failure Module}

\subsubsection{Role in the Model}

The Container Failure module calculates the percentage of containers failing in a period and passes it to the Dissolution and Accounting module. It accounts for containers failing because of corrosion as well as by defects and other means specified by the user. It includes several alternative models of container corrosion that can be selected by the user.

\subsubsection{Internal Modeling and Assumptions}

The most complex models are the models of container corrosion. They are discussed first. At the end of this section, the models of failure due to defects and other unspecified causes are described.

YMIM models several different container corrosion processes. Under dry conditions, only the dry oxidation process is used. Under wet conditions, the user can specify one of the following models: (1) general wet oxidation, (2) general wet oxidation with a pitting factor, or (3) a probabilistic pitting model. Since a container can have two walls, different processes and parameters can be assigned for each wall. Only one process can be active on a wall.

Each of the corrosion models is dependent on temperature. At this time, they are not dependent on other environmental conditions, although the models have been structured to accommodate such extensions in the future. Three of the oxidation models model corrosion rate as a deterministic function. The probabilistic pitting model develops a probability distribution over the rate of penetration, which leads to a probability distribution of the time-to-failure for the walls of the container.

3.7.2.1 Dry Oxidation Corrosion Model. This process is modeled as a temperature-dependent penetration rate. The units for the penetration rate are given in depth/year where the depth may be any unit as long as it is used consistently throughout the modules. The temperature dependence is assumed to be governed by an Arrhenius relationship of the form:

$$
P=k_{1} \exp \left(\frac{-k_{2}}{T}\right)
$$

where

$$
\begin{aligned}
P & =\text { penetration rate (penetration depth/year) } \\
k_{1}, k_{2} & =\text { constants, } \\
T & =\text { temperature }(\mathrm{K}) .
\end{aligned}
$$

To specify the dry oxidation for one wall of the container, the user specifies two sets of penetration rate and temperature. YMIM then computes the values of $k_{1}$ and $k_{2}$.

3.7.2.2 General Wet Oxidation Corrosion Model. The rate of general wet oxidation has an inverted U-shaped relationship with temperature illustrated by Figure 3-1. At lower temperatures the penetration 
rate increases with water temperature. However, as the temperature approaches boiling, the rate reaches a maximum and then begins to decline. This decline is caused by the fact that as water approaches boiling, its ability to transport oxygen to the corroding surface declines.

In the current version of YMIM, this relationship is modeled with a simple quadratic function. To specify the parameters of this model, the user specifies the corrosion rate at some lower temperature (i.e., near ambient), the maximum corrosion rate, and the temperature at which it occurs. YMIM then finds the parameters of the quadratic relationship to specify the model.

3.7.2.3 General Wet Oxidation Corrosion Model with a Pitting Factor. For simple situations, it is useful to take pitting into account in a simple way. This oxidation model is actually a part of the general wet oxidation model described above. In addition to the penetration rate and temperature parameters specified for the general wet oxidation model, the user specifies a "pitting factor" that can account for the increase in penetration rate due to pitting. The penetration rate calculated in the general wet oxidation model is multiplied by this factor. Thus, when the factor is 1.0 , there is no additional penetration due to pitting. If pitting is present, this factor should be greater than 1.0.

3.7.2.4 Probabilistic Aqueous Pitting Corrosion Model. In some cases, the container wall may fail because of pitting, or localized, corrosion. If the user specifies that the probabilistic pitting model is to be used, the Container Failure model estimates the fraction of the containers that have failed because of pitting corrosion in each period. Under this model, it is assumed that a number of pits will form on the surface of the container with varying depths. The container will fail when the deepest pit penetrates the thickness of the container wall. The fraction of containers that have failed in any given period is equal to the probability that the deepest pit on a container is deeper than the wall thickness.

The following discussion outlines the general approach taken in developing the model, and describes the details of the steps and procedures for estimating the required model parameters.

Overview of the Probabilistic Pitting Model. Since failure of a container is due to penetration by the deepest pit on its surface, the model develops a probability distribution over the depth of the deepest pit

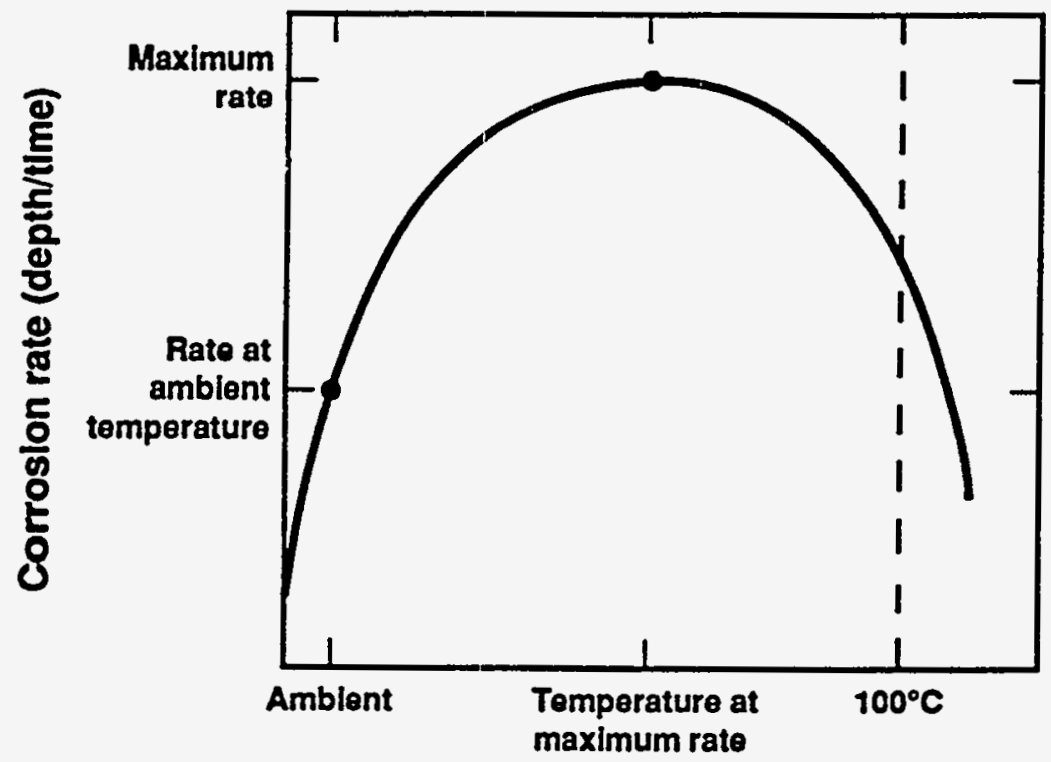

Temperature

Figure 3-1. Rate of general wet oxidation, showing a decline at higher temperatures. The user specifies the rate at $a$ temperature near ambient, the maximum rate, and the temperature at which the maximum occurs.

on a container. This distribution is known as an "extreme value" probability distribution. The complementary cumulative distribution of the extreme value distribution, evaluated at a depth $X$, gives the probability that the deepest pit on a container is deeper than $X$. When $X$ is set equal to the container wall thickness, the complementary cumulative distribution gives the probability that a container has 
failed. By computing the extreme value distribution over pit depth at each period in the model run, we can estimate the fraction of containers that have failed at that period.

The extreme value distribution is derived from the underlying distribution over pit depths on a single container. The depth of a pit at any period is equal to the sum of the incremental amounts that it grew during each preceding period. If these amounts of growth are random and probabilistically independent, then the distribution over total depth will approach a normal distribution after several periods. The discussion below uses an existing stochastic model of pit growth to estimate the shape and the parameters of the underlying distribution over pit depths. It also establishes that the assumption of probabilistically independent growth increments is expected to be valid and, therefore, a normal distribution over pit depth is a valid assumption.

Given that the underlying distribution on pit depths is normal, the depths of the deepest pits on each container will be distributed according the "type 1" extreme value distribution (Gumbel 1954). The parameters of this extreme value distribution are derived using the cumulative distribution of the pit depths.

The last step is the estimation of the parameters of the underlying distribution. The current model takes into account the temperature of the container in estimating the parameters of the distribution. In the future, it is expected that the model will be extended to account for the chemistry of the water in contact with the container.

The sections below describe each of these steps.

Deriving the Underlying Pit Depth Distribution. The first step in deriving the distribution over the depth of the deepest pit on a container is to derive the distribution over the depth of any randomly selected pit on a container. This distribution is referred to as the "underlying distribution." The derivation is based on a stochastic model for pit initiation and growth described by Henshall et al. (1993), which models both the formation and growth of pits as a stochastic process. The model reproduces actual distributions of pit depths fairly well, and thus its underlying assumptions appear to be approximately correct.

Under this model, there is a probability that a pit will be initiated and a probability that the pit will eventually become "stable" and continue to grow. If the pit does not become stable, it does not grow. This analysis is concerned only with the growth process for the stable pits.

The stochastic model proposed by Henshall et al. suggests that the pits grow in increments. Time is divided into small steps (i.e., time steps that are small compared with the entire period being modeled). There is a probability that the pit will grow during each time step. If it does grow, it grows by one unit. Otherwise it does not grow at all. The probability that a pit grows is denoted by $\gamma$, which can be a function of the chemical and thermal environment. A key assumption of the model is that the probability of growth in any one period is independent of growth in previous time steps.

The Henshall model assumes that pit growth occurs in unit increments. The depth of a pit is thus numerically equal to the number of times it has grown. The analysis also assumes that the number of time steps in a period is given (although this number is varied across the cases analyzed). With these assumptions, the probability distribution over pit growth during a time period is binomial, i.e., the sum of a series of Bernoulli trials. The distribution is of the form:

$$
p(x)=\frac{s !}{x !(s-x) !} \gamma^{x}(1-\gamma)^{s-x}
$$

where

$x=$ the depth of the pit in terms of the number of growth increments that occurred (equivalent to the number of successful trials),

$s=$ the number of steps in the period (equivalent to the number of Bernoulli trials),

$\gamma=$ the probability of growth during a step.

In order to use this model, it is necessary to calibrate it using data or expert judgments about growth. Calibration is performed by estimating the mean and variance of the actual growth and then fitting the parameters of the distribution to a given distribution over growth with the same mean and variance. This 
calibration can be done with the binomial model, since there are two parameters to the model and the distribution to be fitted has two parameters, but the results do not always make physical sense. In particular, negative values of $\gamma$ are obtained if the variance is much larger than the mean.

Because YMIM is designed to model corrosion as a function of the environment (only temperature is currently accounted for), future versions are also expected to account for water chemistry. It is expected that both the likelihood of growth during a period and the amount of growth-given the occurrence of growth-will vary with changes in the environment. Therefore, the model should be extended by allowing the incremental growth to be specified as a parameter (instead of assuming that it is equal to unity as Henshall et al. do).

However, if the binomial growth model were extended by adding the growth increment as a third parameter, it would not be practical to try to match a distribution over actual growth. The distribution over actual growth is specified by its mean and variance, while the model based on the binomial would be specified by three parameters. Consequently, the system would be underdetermined, and unique values for the parameters could not be found.

These problems can be avoided by using a model based on a Poisson distribution over the number of growths during a period of time. The Poisson distribution is the distribution over the number of successes in a period, given the expected number of successes during the period. A Poisson distribution is closely related to a binomial-the binomial distribution converges to the Poisson distribution as the number of trials during a time period is increased and the probability of success per trial is decreased, so that the expected number of successes during the time period is constant. Thus the Poisson distribution is characterized by a single parameter: the expected number of successes per unit time.

In addition to assuming the Poisson distribution over the number of growths in a period of time, the growth per increment is also a parameter.

The Poisson distribution $p(x)$ over the number of growths, its mean $E(x)$, and its variance $V(x)$ are given by:

$$
p(x)=\frac{(\rho t)^{x} e^{-\rho t}}{x !}
$$

and

$$
\begin{aligned}
& E(x)=\rho t \\
& V(x)=\rho t
\end{aligned}
$$

where

$x=$ the growth of the pit in units of additional depth,
$\rho=$ the expected number of growth increments per period of time (e.g., per year),
$t=$ the length of the time period (yr).

Equation (3-3) gives the distribution over the number of times a pit grows. To derive the distribution over the depth of the pit, it is necessary to define the unit of growth that occurs each time the pit grows. Let this unit be $g$ (a unit of length). Then the expected value $E\left(d_{i}\right)$ and variance $V\left(d_{i}\right)$ of the growth during the period can be derived as:

$$
\begin{aligned}
& E\left(d_{i}\right)=g_{i} \rho_{i} t_{i} \\
& V\left(d_{i}\right)=g_{i}^{2} \rho_{i} t_{i}
\end{aligned}
$$

where

$$
d_{i}=\text { the total amount of growth during period } i \text {, }
$$


$g_{i}=$ the increment of growth during one time step, given that the pit grows during period $i$,

$\rho_{i}=$ the expected number of growth events per unit time during period $i$,

$t_{i}=$ the length of period $i(\mathrm{yr})$.

When $g$ is defined to be unity, as was done in the Henshall study, the mean and the variance are numerically equal.

In the Henshall paper, several histograms of measured pit depths are presented from various experiments. Distributions based on the Poisson, with suitable values for $\rho$ and $g$, agree closely with these measured distributions, suggesting that the pit growth model based on the Poisson distribution is valid.

Deriving the distribution over growth using the Poisson model allows us to define the distribution in terms of the parameters of an underlying model of pit growth, $g_{i}$ and $\rho_{i}$. We can model the effect of environmental conditions on corrosion rates by modeling their effect on these parameters. This modeling is done by estimating the parameters at two different environmental conditions and then interpolating for intermediate conditions. The interpolations are based on functions derived from the underlying physical mechanisms. For example, the current version of YMIM accounts for the effect of temperature. In this case, it is assumed that both $g$ and $\rho$ vary with temperature according to an Arrhenius relationship of the form:

$$
g(T)=k_{1} \exp \left(-k_{2} / T\right)
$$

where

$g(T)=$ the incremental growth as a function of temperature,

$k_{1}, k_{2}=$ constants.

Over many periods, the depths of the pits are equal to the sum of the depths added during each period. Although the distribution over the depths added in each period is a Poisson distribution, the sum of the depths over many periods will approach a normal distribution since the amounts added are independent of each other. Therefore, the probability distribution over the total pit depth is a normal distribution whose mean $\mu$ and variance $\sigma$ are given by:

$$
\begin{aligned}
& \mu=\sum_{i=1}^{n} g_{i} \rho_{i} t_{i} \\
& \sigma^{2}=\sum_{i=1}^{n} g_{i}^{2} \rho_{i} t_{i}
\end{aligned}
$$

The amount of time in an interval during which the container is wet, $t_{i}$, is the actual interval length multiplied by the fraction of time during that interval that the container is wetted. Information about container wetting is supplied to the Container Failure module by Near-Field Hydrology.

Methods for determining $g_{i}$ and $\rho_{i}$ are discussed below.

Deriving the Extreme Value Probability Distribution Over the Depths of the Deepest Pits. For this analysis, we are concerned with the fraction of containers that are penetrated by pitting corrosion during each time period. Another way of putting it is to say that we are concerned only with the probability that the deepest pit on a container is deeper than the thickness of the container wall. Therefore, we need to compute the probability distribution over the depths of the deepest pit on each container. Given this distribution, we can calculate the fraction of containers whose deepest pit is greater than the thickness of the wall. This number gives the fraction of containers that have failed. To reiterate, the population of interest is the deepest pit on each container.

The distribution over the depths of the deepest pit is an "extreme value distribution." Because the underlying distribution on pit depth is a normal distribution, the distribution over the extreme values approaches a "Type 1" asymptotic extreme value distribution (Gumbel 1954). The extreme value 
distribution is based on the following sampling procedure. Groups of samples are chosen at random (in this case each pit is a sample, and all the pits on a single container is the group). The largest sample in each group is selected, i.e., the deepest pit on each container. The extreme value distribution is the distribution over these largest samples (deepest pits). The cumulative distribution function $\Phi(x)$ and density distribution function $\Phi^{\prime}(x)$ for the Type 1 extreme value distribution are given by:

$$
\begin{aligned}
& \Phi(x)=e^{-e^{-y}} \\
& \Phi^{\prime}(x)=\phi(x)=\alpha_{n} e^{-y-\left(e^{-y}\right)}
\end{aligned}
$$

where

$x=$ value of the largest sample in a group (in this case, the largest pit depth),

$y=$ normalized variate, $\alpha_{n}\left(x-\mu_{n}\right)$,

$\mu_{n}=$ expected largest value, ${ }^{*}$

$a_{n}=$ a measure of the dispersion of the distribution,

$n=$ the number of samples in each group (i.e., number of pits on a container).

Note that both $\mu_{n}$ (expected largest value) and $\alpha_{n}$ (related to dispersion of the distribution) are functions of $n$.

Gumbel specifies the procedures for calculating $\mu_{n}$ and $\alpha_{n}$ of the extreme value function. The following relationships are used to define $\mu_{n}$ and $\alpha_{n}$ :

$$
\begin{aligned}
& F\left(\mu_{n}\right)=1-\frac{1}{n}, \\
& \alpha_{n}=n f\left(\mu_{n}\right),
\end{aligned}
$$

where $F\left(\mu_{n}\right)$ is the cumulative density function $(\mathrm{cdf})$ of the underlying distribution, i.e., the normal distribution over pit depths, and $f\left(\mu_{n}\right)$ is the probability density function (pdf) of the underlying distribution. From Eq. (3-13), $\mu_{n}$ is the value of $x$ such that the cumulative probability of the underlying distribution is $(1-1 / n)$. This value is equivalent to the value of $x$ such that the complementary cumulative, $Q(x)$, is $1 / n$.

Since the distribution of pit depths is normal, the cumulative distribution cannot be computed analytically. However, Abramowitz and Stegun (1964) provide a numerical approximation to the required function:

$$
\tilde{x}(p)=t-\frac{c_{0}+c_{1} t+c_{2} t^{2}}{1+d_{1} t+d_{2} t^{2}+d_{3} t^{3}}+\varepsilon(p)
$$

where

$$
\begin{aligned}
\tilde{x}(p) & =\text { the value of the normalized variate such that the value of the complementary cumulative } \\
p & =\text { probability equals } p \\
t & =\sqrt{\ln \left(1 / p^{2}\right)}
\end{aligned}
$$

and

$$
c_{0}=2.515517 \text {, }
$$

- Gumbel calls this the "expected largest value" However, he points out that it is not the same as the mean largest value (Gumbel 1954, p. 13). 


$$
\begin{aligned}
& c_{1}=0.801853 \\
& c_{2}=0.010328 \\
& d_{1}=1.432788 \\
& d_{2}=0.189269 \\
& d_{3}=0.001308
\end{aligned}
$$

The error in this approximation is given by:

$$
|\varepsilon(p)|<4.5 \times 10^{-4}
$$

In Eq. (3-15), the variate, $\tilde{x}$, is normalized by the mean and the standard deviation.

The mean of the extreme value distribution is the value that satisfies the following equation, where $\tilde{\mu}_{n}$ is the mean of the extreme value distribution normalized by the mean and the standard distribution of the underlying distribution:

$$
Q\left(\tilde{\mu}_{n}\right)=1-F\left(\tilde{\mu}_{n}\right)=1-\left(1-\frac{1}{n}\right)=\frac{1}{n}
$$

Therefore

$$
\tilde{\mu}_{n}=t-\frac{c_{0}+c_{1} t+c_{2} t^{2}}{1+d_{1} t+d_{2} t^{2}+d_{3} t^{3}}+\varepsilon\left(\frac{1}{n}\right)
$$

where

$$
t=\sqrt{\ln \left(\frac{1}{n}\right)^{-2}}=\sqrt{\ln \left(n^{2}\right)}
$$

The un-normalized value of the mean of the extreme value distribution is computed as:

$$
\mu_{n}=\bar{\mu}_{n} \sigma_{u}+m_{u}
$$

where

$\sigma_{\mathcal{u}}=$ the standard deviation of the underlying distribution on pit depth,

$m_{u}=$ the mean of the underlying distribution on pit depth.

The mean and variance of the underlying distribution are given by Eqs. (3-9) and (3-10). During each period, $p_{i}$ and $g_{i}$ are computed as described below. Next, Eqs. $(3-6)$ and $(3-7)$ are used to determine the mean and variance of the distribution on the increase in pit depths during the interval. Equations (3-9) and $(3-10)$ are then used to determine the mean and variance of the cumulative pit depth distribution. Next, a new $\mu_{n}$ and $\alpha_{n}$ are calculated for the extreme value function using the equations above. Finally, the cumulative of the extreme value function, Eq. (3-11), is used to determine the distribution of the deepest pits on the container surface and the probability that a container has failed.

Determining Parameter Values for the Probabilistic Pitting Model. In this model, the values for $g_{i}$ and $p_{i}$ must be determined for each period in a model run. In principle, the values of these parameters can be estimated from experimentation or from theories of the dynamics of the chemistry of pit growth. At present, little or no data is available for the alloys and time spans of interest. Expert opinion based on experimental data and theoretical considerations can be a basis for estimating the parameters at this time. This section discusses procedures for setting the parameter values based on these approaches. 
The values of $g$ and $\rho$ can be calculated from data or judgments about the mean and variance of the growth rates of pits using Eqs. (3-6) and (3-7). These equations give the mean and variance of the distribution over growth in terms of $g_{i}$ and $\rho_{i}$. We observe that there are two equations and two unknowns (i.e., $g_{i}$ and $p_{i}$ ). The value of $t$ is not an unknown since it is the length of the period that is fixed. (In much of the following discussion, we assume that the length of the period is one year, so that the results are in terms of growth per year.)

The current version of the model includes the response of corrosion to temperature through the estimates of $g_{i}$ and $p_{i}$. The temperature dependence is based on an Arrhenius relationship between $\gamma$, applied voltage, chloride concentration, and temperature suggested by Henshall et al.:

$$
\gamma=A_{4}\left(E_{\text {app }}-B_{4}\right)^{B_{5}} \cdot\left[\mathrm{C}^{-}\right]^{C_{4}} \cdot \exp \left(Q_{\gamma} / R T\right)
$$

where

$$
\begin{aligned}
E_{\mathrm{app}} & =\text { applied potential, } \\
{\left[\mathrm{Cl}^{-}\right] } & =\text {chloride concentration, } \\
A_{4}, B_{5}, C_{4} & =\text { constants, } \\
\mathrm{Q}_{\gamma} & =\text { activation energy, } \\
R & =\text { universal gas constant, } \\
T & =\text { temperature }(\mathrm{K}) .
\end{aligned}
$$

In the original model of Henshall et al., $\gamma$ is the probability of growth during a time step. In the modified model suggested here (based on the Poisson distribution), the parameter $\rho$ is just $\gamma$ multiplied by time. Consequently, it is assumed here that $\rho$ also has an Arrhenius relationship with temperature.

The current model assumes that applied potential and chloride concentration are constant. But it does incorporate the Arrhenius relationship between $\rho$ and temperature suggested by the above equation. In addition, it is assumed that there is an Arrhenius relationship between $g$ and temperature. We can write $g_{i}$ and $p_{i}$ as a function of temperature using the following equations:

$$
\begin{aligned}
& \rho_{i}\left(T_{i}\right)=k_{\rho 1} \exp \left(\frac{k_{\rho 2}}{T_{i}}\right) \\
& g_{i}\left(T_{i}\right)=k_{g 1} \exp \left(\frac{k_{g 2}}{T_{i}}\right)
\end{aligned}
$$

The user specifies the values of $g$ and $\rho$ at two different temperatures. The model then calculates the values of the $k s$ as part of its initialization. From these it can compute the values of $g$ and $\rho$ at any other temperature.

Preparing the input for the model requires estimating $g$ and $\rho$ at two different temperatures. These values can be determined by estimating values of the mean and variance of pitting depth at two different temperatures. Thus, if values are assumed for the average annual pitting depth at $T_{1}$ and $T_{2}\left[E_{d}\left(T_{1}\right)\right.$ and $\left.E_{d}\left(T_{2}\right)\right]$ and the variances of the annual pitting depth $\left[V_{d}\left(T_{1}\right)\right.$ and $\left.V_{d}\left(T_{2}\right)\right]$, we have the following four equations:

$$
\begin{aligned}
& E_{d}\left(T_{1}\right)=g\left(T_{1}\right) \rho\left(T_{1}\right) t \\
& V_{d}\left(T_{1}\right)=g\left(T_{1}\right)^{2} \rho\left(T_{1}\right) t
\end{aligned}
$$


and

$$
\begin{aligned}
& E_{d}\left(T_{2}\right)=g\left(T_{2}\right) \rho\left(T_{2}\right) t \\
& V_{d}\left(T_{2}\right)=g\left(T_{2}\right)^{2} \rho\left(T_{2}\right) t
\end{aligned}
$$

Since the average pitting depths and the variance of the pitting depth have been defined as the annual average and variance, $t$ is known to be 1 .

Solving Eqs. (3-22) through (3-25) yields $g\left(T_{1}\right), \rho\left(T_{1}\right), g\left(T_{2}\right)$, and $\rho\left(T_{2}\right)$. These values are then input to YMIM, which solves Eqs. (3-20) and (3-21) to calibrate the functions that give $g$ and $\rho$ as a function of temperature.

3.7.2.5 Failures Due to Defects and Unspecified Causes. The containers can also fail because of defects. It is assumed that such failures will occur at a higher rate earlier in the repository history, and so an exponentially declining rate of failure is used. The user specifies the total percent of containers that will fail because of defects and the parameter of the exponential distribution. At each period, YMIM calculates the percent of containers failing from the distribution.

Containers that fail because of unspecified mechanical causes are modeled as failing at a uniform rate over a period of years. The user specifies the percent of containers that will fail because of unspecified causes and the years that the failures begin and end.

\subsubsection{Parameters, Input Variables, and Output Variables}

\section{Input Parameters}

General Parameters

- Containers failing by defect (fraction).

- Containers failing by unspecified mechanical causes (fraction).

- Beginning time for unspecified mechanical failures (yr).

- Ending time for unspecified mechanical failures (yr).

- Parameter for exponential defective failure distribution (dimensionless).

- Number of pits on container surface (\#).

- Number of container walls (\#: either 1 or 2).

\section{Parameters Describing Corrosion of the Outer Wall}

- Thickness of the outer container wall $(\mathrm{cm})$.

- Flag to indicate whether or not dry oxidation is active on the outer wall (enter $Y$ or $N$ ).

- Oxidation temperature $1\left({ }^{\circ} \mathrm{C}\right)$.

- Oxidation rate at temperature $1(\mathrm{~cm} / \mathrm{yr})$.

- Oxidation temperature $2\left({ }^{\circ} \mathrm{C}\right)$.

- Oxidation rate at temperature $2(\mathrm{~cm} / \mathrm{yr})$.

- Flag to indicate whether or not general aqueous corrosion is active on the outer wall (enter Yor N).

- General aqueous corrosion rate at $20^{\circ} \mathrm{C}$.

- Temperature at which the peak general aqueous corrosion rate occurs $\left({ }^{\circ} \mathrm{C}\right)$.

- General corrosion rate at peak temperature $(\mathrm{cm} / \mathrm{yr})$.

- Pitting factor (factor $\geq 1.0$, no pitting corresponds to a factor of 1.0).

- Flag to indicate whether or not probabalistic pitting model is active on the outer wall (enter Y or N).

- Localized corrosion temperature $1\left({ }^{\circ} \mathrm{C}\right)$.

- Incremental growth at temperature $1(\mathrm{~cm})$.

- Expected number of growths per year at temperature 1 .

- Localized corrosion temperature $2\left({ }^{\circ} \mathrm{C}\right)$.

- Incremental growth at temperature $2(\mathrm{~cm})$.

- Expected number of growths per year at temperature 2. 


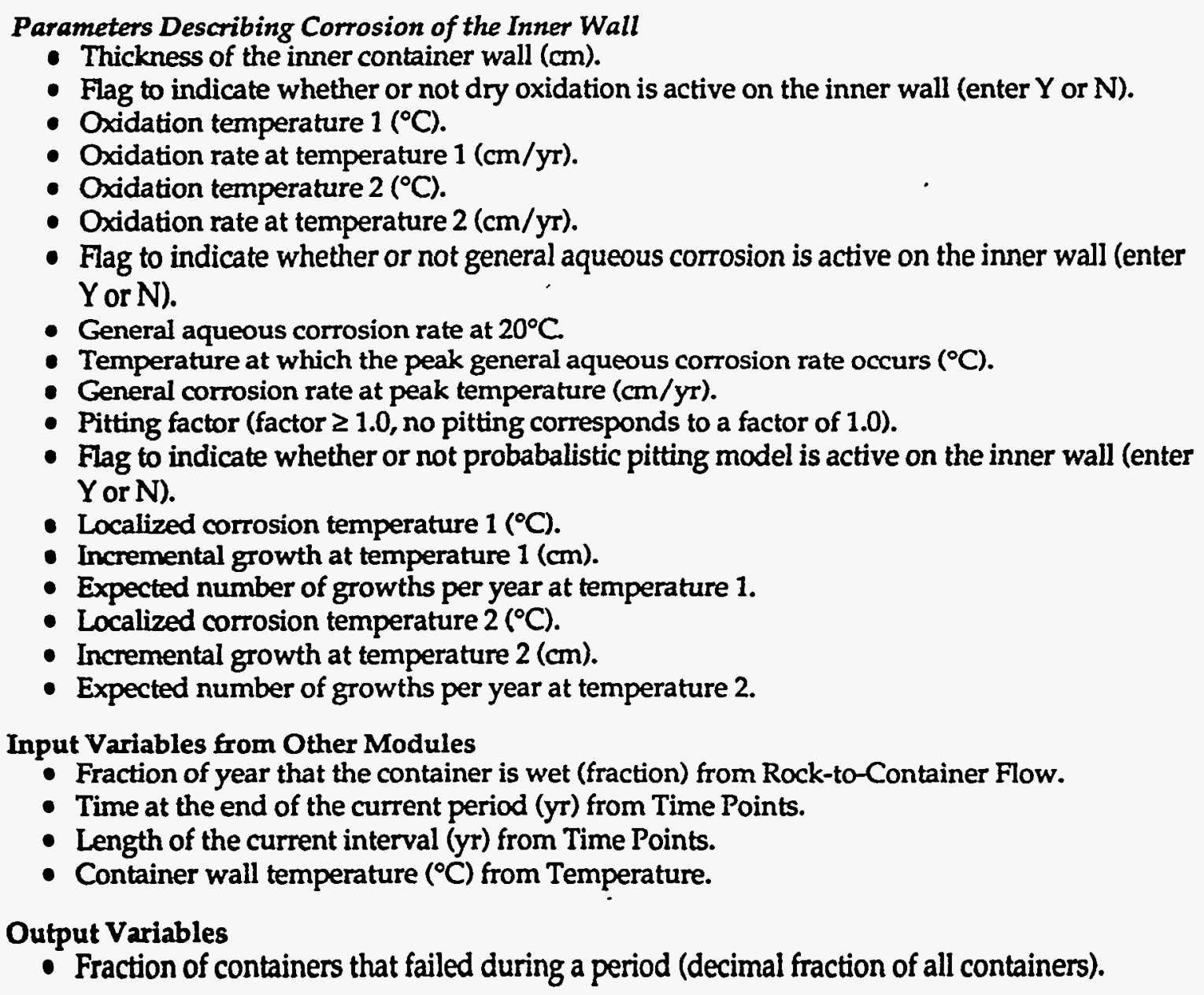

\subsection{Internal Container Flow Module}

\subsubsection{Role in the Model}

The Internal Container Flow module models the flow over the fuel rods in failed containers. It determines the area of the fuel matrix per fuel rod exposed as a result of cladding failure, the size of the exposed area that is wetted, and the volume of flow over the exposed area. These values are used to compute the rate of dissolution in the Dissolution and Accounting module.

\subsubsection{Internal Modeling and Assumptions}

It is assumed that after the cladding fails on a fuel rod, part of the spent fuel will be exposed to water when there is flow into the container. In the current module, the amount of area exposed is estimated by calculating the area that would be exposed if the entire rod were to oxidize to $\mathrm{U}_{3} \mathrm{O}_{8}$. This would lead to a volumetric expansion, and the cladding would no longer cover the entire surface of the fuel pellets. The area exposed is computed as the difference between the surface area of the expanded waste form and the original area of the waste form. In the current module, it is assumed that the entire exposed area is wetted when water enters the container. The volume of water flowing over the exposed area is calculated assuming that the water is uniformly distributed over and flowing along the surface of the fuel rod. Thus the fraction of the water that actually flows over the exposed area is equal to the fraction of the waste form surface that is exposed. 


\subsubsection{Parameters, Input Variables, and Output Variables}

\section{Input Parameters}

- Volumetric expansion of the waste form upon oxidation (decimal fraction > 1.0).

- Initial cross-sectional area of a fuel pellet $\left(\mathrm{m}^{2}\right)$.

- Rod length (m).

\section{Input Variables from Other Modules}

- Water flow into the container (liters/yr) from Rock-to-Container Flow.

\section{Output Variables}

- Wetted surface area of the fuel matrix in a single fuel rod with failed cladding $\left(\mathrm{m}^{2}\right)$.

- Exposed surface area of the fuel matrix in a single fuel rod with failed cladding $\left(\mathrm{m}^{2}\right)$.

- Total surface area of the fuel matrix in a single fuel rod with failed cladding $\left(\mathrm{m}^{2}\right)$.

- Fraction of surface area of the fuel matrix exposed in fuel rods with failed cladding(fraction).

- Total water flow onto fuel matrix of all fuel rods with failed cladding (liters/yr).

- Surface area of cladding of a single fuel rod $\left(\mathrm{m}^{2}\right)$.

\subsection{Cladding Failure Module}

\subsubsection{Role in the Model}

The Cladding Failure module models the failures of fuel rod cladding inside a waste container. It is called by the Dissolution and Accounting module and provides the fraction of rods failing in a container during a given period.

\subsubsection{Internal Modeling and Assumptions}

In the current Cladding Failure module, three mechanisms can cause the fuel rod cladding to fail. Each mechanism is only active under specific conditions. These conditions are specified in the input file and are:

(1) Minimum temperature for creep failure to occur, $t_{c}$.

(2) Minimum temperature for hydride failure to occur, which is equal to the boiling temperature of water, $t_{\mathrm{b}}$.

(3) Minimum concentration of fluorine for failure by contact with fluorinated water.

The mechanisms and the conditions necessary for their activation are:

- High-temperature creep: cladding temperature $\geq t_{c}$.

- Hydride reorientation: $t_{\mathrm{b}} \leq$ cladding temperature $<t_{\mathrm{c} \text {. }}$

- Fluorine contact: water in contact with the cladding and fluorine concentration greater than or equal to the specified limit.

After emplacement occurs, the average repository temperature will rise and peak early in the repository lifetime, driving any ambient water from the repository horizon. Therefore, in the current model we assume that no container can come into contact with liquid water until the average repository temperature drops below $t_{b}$. As a result, we can divide the repository cladding failure history into periods during which only one failure mechanism is active. These periods are defined by temperature and wetting conditions as follows:

- From ambient temperature to $t_{b}$ : no failures.

- From $t_{\mathrm{b}}$ to $t_{\mathrm{c}}$ : hydride failures.

- Between $t_{c}$ and peak temperature: creep failures.

- From $t_{\mathrm{c}}$ to $t_{\mathrm{b}}$ : hydride failures.

- From $t_{b}$ to ambient: fluorine failures (if water conditions are appropriate).

Figure 3-2 illustrates these ranges.

The failure rate for each mechanism is specified in a file read by Cladding Failure. The failure models for hydride and creep failures are specified by two parameters: (1) the maximum percentage of rods that could fail by that mechanism (it is assumed that even if the mechanism were to continue indefinitely, only 
a percentage of the rods would fail by that mechanism), and (2) the time required for the maximum percentage of failures to occur by that mechanism. The failure rate is therefore given by

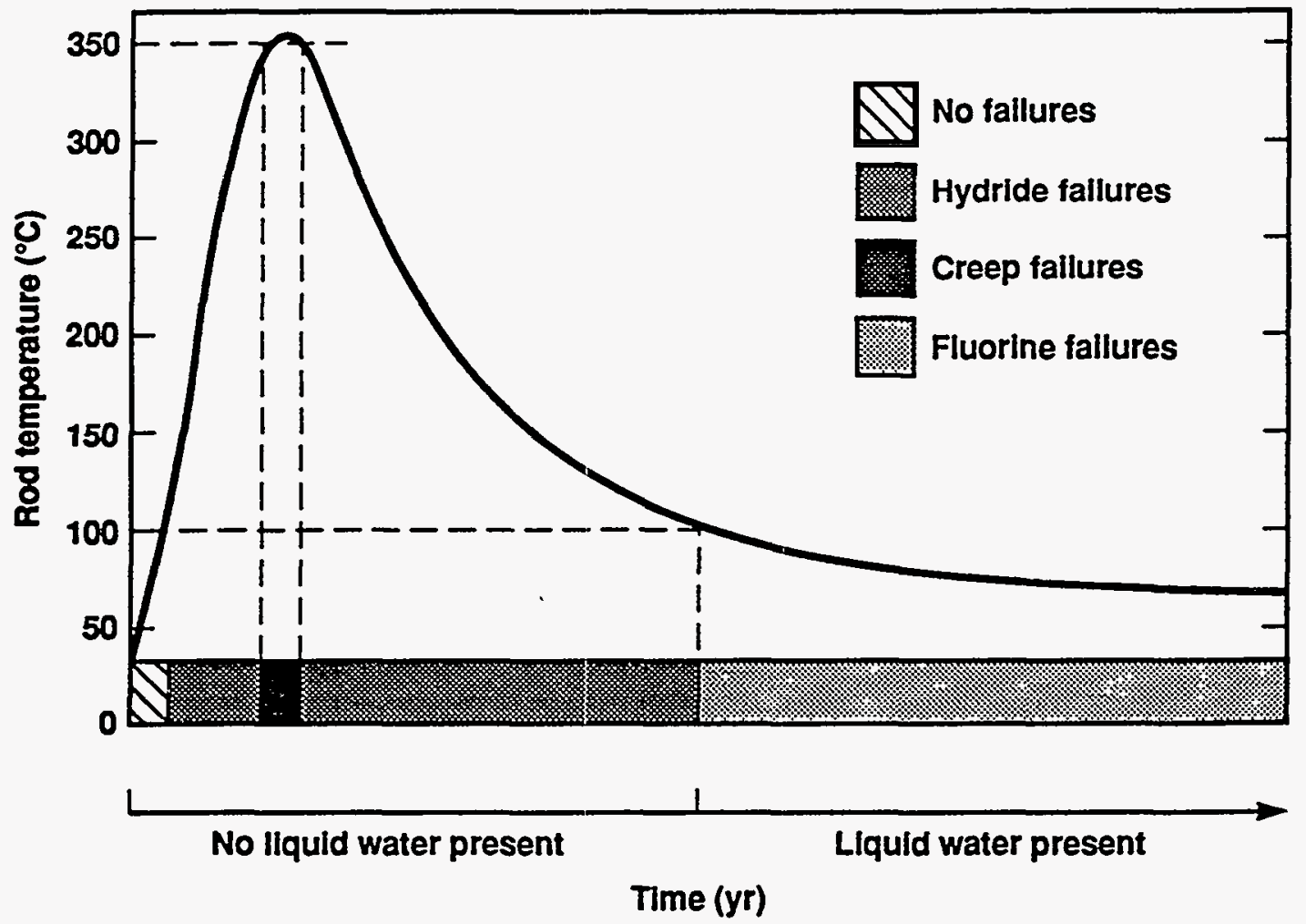

Figure 3-2. Failure mechanisms as a function of rod temperature.

Failure rate $(\% / y r)=\frac{\text { percentage of rods assumed to fail }}{\text { time period over which failures occur }}$

If fluorine is present and the rods are in contact with groundwater, it is assumed that all of the rods that have not failed by other mechanisms will eventually fail because of the fluorinated water. It is important to note that if the average repository temperature is not within the particular mechanism's temperature range for a long enough period to cause failure of the maximum percentage of the rods that can fail by that mechanism, the total percentage of rods actually failing by that mechanism will be some fraction of the maximum percentage. As a result, we do not specify a fraction of rods that will fail by fluorine contact, but instead assume that any rods that do not fail by the other mechanisms may fail by contact with fluorinated water, if it is present, since no other failure mechanism can be activated once the rods are in the fluorine failure region. Therefore, only a time period for failure is specified in the case of fluorine failures, and the failure rate is given by:

$$
\text { Fluorine failure rate }(\% / \mathrm{yr})=\frac{\text { percent of rods that have not failed by other mechanisms }}{\text { time period over which failures occur }}
$$

The Cladding Failure module is called from within the Dissolution and Accounting module. As discussed in the section on the Dissolution and Accounting module (Sec. 3.10), the containers are grouped according to time of corrosion failure. When the Cladding Failure module is called, it returns the fraction of rods failing for each group of containers. For creep and hydride failures, this fraction is the same for all groups of containers since the failure mechanisms do not require container failures to be active. For fluorine 
failures, the failure percentage is only assigned to groups of containers that have failed and are in contact with water with fluorine concentrations above the cutoff. Unfailed containers are assigned a zero fluorine failure fraction.

\subsubsection{Parameters, Input Variables, and Output Variables}

\section{Input Parameters}

- Lower temperature limit for failure by creep rupture $\left({ }^{\circ} \mathrm{C}\right)$.

- Lower temperature limit for failure by hydride reorientation $\left({ }^{\circ} \mathrm{C}\right)$.

- Fraction of rods that can fail by creep rupture (decimal fraction).

- Fraction of rods that can fail by hydride reorientation (decimal fraction).

- Minimum fluorine concentration for failure by contact with fluorinated water (ppm).

- Time period over which creep rupture failures occur (yr).

- Time period over which hydride reorientation failures occur (yr).

- Time period over which fluorine failures occur (yr).

\section{Input Variables from Other Modules}

- Length of each time period (yr) from Time Points.

- Cladding surface temperature $\left({ }^{\circ} \mathrm{C}\right)$ from Temperature.

- Fluorine concentration (ppm) from Near-Field Chemistry.

\section{Output Variables}

- Fraction of fuel rods whose cladding failed during the period, for a container that failed during a specific period (decimal fraction).

\subsection{Dissolution and Accounting Module}

\subsubsection{Role in the Model}

The Dissolution and Accounting module models the internal state of the waste container and computes the release rate of nuclides into the near-field environment. It tracks the state of fuel matrix and the nuclides contained in them, models the dry oxidation and aqueous alteration of the waste form, and models the aqueous and gaseous release of nuclides. To do this, it also tracks the failure of the waste containers by calling the Container Failure module.

\subsubsection{Internal Modeling and Assumptions}

Dissolution and Accounting computes the mass release rate of nuclides from the container during each time interval. For nuclides to be released from the waste form, the following events must occur:

- The waste package fails.

- The fuel-rod cladding fails.

- The nuclides are freed from the $\mathrm{UO}_{2}$ fuel matrix by aqueous alteration or air oxidation. Once these events have occurred, nuclides are available for transport from the waste package.

The rate of aqueous alteration is modeled as a function dependent on temperature, chloride concentration, and pH. Dry oxidation of the fuel matrix is modeled as a temperature-dependent process. Aqueous transport of the nuclides is a function of the solubility limit and the rate at which nuclides are freed from the fuel matrix. Gaseous release is dependent on the rate of container and cladding failure.

The discussion describes (1) the internal data structure of the Dissolution and Accounting module, and (2) the processes that free the nuclides from the fuel matrix and transport them from the failed waste packages.

3.10.2.1 Internal Structure of the Dissolution and Accounting Module. The Dissolution and Accounting module tracks the history of all the containers that fail during a model run. The module contains a number of temperature-dependent mechanisms that require the availability of atmospheric oxygen in a failed waste package. The temperature at which these processes become active is a function of the time of container failure. In order to properly track the internal state of a waste package, it is 
necessary to divide the waste packages into "container groups" by the time of container failure. There is one container group for each period (as specified in the Time Points module).

Each group tracks the state of the containers that failed in one period. Within a container group, the model keeps track of the fraction of containers represented by that group, the fraction of fuel rods in a representative container with failed cladding, and the amount of each nuclide altered or oxidized. All of the containers in a group experience the same history. (Note that all containers in a YMIM run experience the same repository conditions, i.e., hydrology, chemistry, and temperature scenarios. Only the period in which the container fails distinguishes between container groups.) Therefore, all containers within a group have the same number of fuel rods with failed cladding, the same amount of material altered, and so forth.

The module is built around an array of data elements that has one element for each period. Each element tracks the history for a group of containers that failed in a given period-that is, the ith element tracks the history of the containers that failed in the $i$ th period.

The inventories of nuclides in a container can exist in several states. Each period, a portion of each nuclide moves from one state to another. To keep track of the transitions occurring to the nuclides in a container, the following states have been defined:

- Unfailed mass. Inventory of nuclide contained in fuel rods with unfailed cladding.

- Failed mass. Inventory of nuclide contained in fuel rods with failed cladding that has not been altered or oxidized.

- Oxidized mass. Inventory of nuclide that has been oxidized and is available for transport.

- Altered mass. Inventory of nuclide that has been altered and is available for transport.

The mass of each nuclide in each state is tracked by the module. To more easily calculate release, the following variable is also tracked:

- Original mass. Initial inventory of nuclide present in a waste package.

In addition, each element contains the following information about the state of the fuel rods and container:

- Containers failed. Fraction of containers represented by the array element.

- Current cladding failures. Fraction of fuel rods in a representative container whose cladding failed in the current period.

- Cumulative cladding failures. Cumulative fraction of fuel rods with failed cladding in a container.

With the exception of 'containers failed,' all state variables modeled are updated during a tirne step to represent the new internal state of the waste package. Since a grouping of containers consists of all containers that failed at the same point in time, once 'containers failed' is assigned, it does not change for the remainder of the model run.

As time progresses, the mass of each nuclide gradually moves from one state to another. Transitions between these states are governed by a set of mechanisms including cladding failure, waste form oxidation, waste form alteration, gaseous release, and aqueous release. Figure 3-3 shows the set of possible transitions between states. Once the fuel rod cladding has failed for a portion of the rods, mass in those rods is moved from the state 'unfailed mass' to 'failed mass.' For nuclides to be released from a fuel rod with failed cladding, they must first be freed from fuel matrix by either aqueous alteration, air oxidation, or the pulse release mechanism. Alteration and oxidation are represented in the state transition diagram by a transition from 'failed mass' to either 'altered mass' or 'oxidized mass.' Nuclide mass in the 'altered mass' and 'oxidized mass' states is available for transport by aqueous and gaseous release mechanisms. Material that is in the fuel cladding gap can be directly released without going through the 'altered' or 'oxidized' states.

Figure $3-4$ shows the numerical relationship between the 'original mass' in a container and the portions of the mass that are in each of the states, plus the mass that has been released. Nuclide decay is calculated for all elements of the accounting structure at the end of each period, including the 'original mass' (i.e., the variable 'original mass' at each period is equal to the amount of the original mass from the previous period after subtracting out decay). Therefore, the amount of nuclide decay is not represented in Fig. 3-4. 


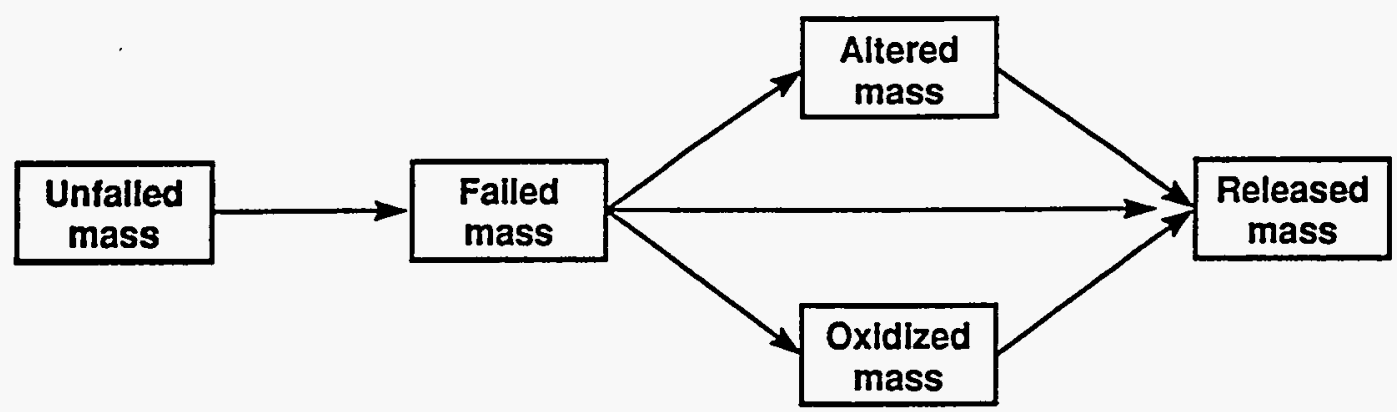

Figure 3-3. State transition diagram.

3.10.2.2 Outline of the Calculation Steps for Each Period. During each period of a model run, each container group (i.e., data element) is updated by determining the number of new rods failing, mass of nuclides altered, mass of nuclides oxidized, nuclide dissolution, and nuclide decay occurring in a representative container. In addition, during the $j$ th period of the run, the number of containers failing during that period is calculated and assigned to the $j$ th group of containers (i.e., the $j$ th data element).

During a given period, some of the container groupings represent containers that have not yet failed. Consequently, there is no alteration or dissolution of nuclides in them. Also, since a group of containers consists of all containers that failed at the same point in time, once 'containers failed' is assigned to that group, it does not change for the remainder of the model run.

The specific calculation steps during the $j$ th period of a model run are as follows:

(1) For every data element (all failed and unfailed containers):

- Calculate the fraction of fuel rods failing during the current period.

- Calculate the amount of each nuclide decayed in each state.

(2) For the $j$ th data element only (element representing containers failing in the current period):

- Calculate the fraction of containers failing during the current period.

- Calculate gaseous release at container failure.

(3) For data elements 1 through $j$ (elements representing containers that have failed):

- Calculate the amount of each nuclide oxidized.

- Calculate the amount of each nuclide altered.

- Calculate aqueous release.

- Calculate gaseous release upon cladding failure.

Release calculations assume that each data element represents a single container. Therefore, total release from a data element is the product of the fraction of containers represented by that element and the calculated release. Total release for a period is the sum of the releases from the individual elements.

The following sections describe the modeling for these steps in more detail.

3.10.2.3 Calculation of Container and Cladding Failures. At the start of calculations during time step $j$, Dissolution and Accounting calls the Container Failure module, which returns the fraction of containers failing during the current period. This information is then stored in the variable 'container failures' of the $j$ th element of the dissolution accounting array, which represents containers failing during the current period.
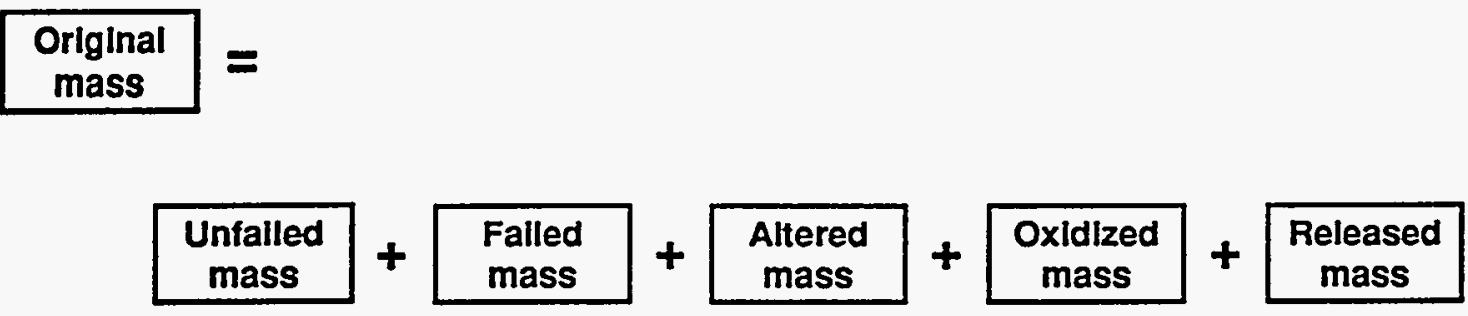

Figure 3-4. Numerical relationship between states. 
After determining the fraction of containers failing during the current period, Dissolution and Accounting calls the Cladding Failure module to determine the fraction of fuel rods failing in each group of containers during the current period. Since the fraction of rods failing is a function of the state of the container (only failed containers may have cladding failures due to contact with fluorinated water), one call is made to the Cladding Failure module for each element of the dissolution accounting array. The value returned is stored in the variable 'cladding failures this period,' and 'cumulative cladding failures' is updated.

Once the fraction of rods failing during the current period is determined, the appropriate amount of mass is moved from state 'unfailed mass' to state 'failed mass' for each element of the accounting structure. The amount moved is mass in state 'original mass' multiplied by the fraction of rods failing during the current period.

3.10.2.4 Calculation of $W$ aste-Form Oxidation and Alteration. For nuclides to undergo aqueous release, a fuel form state transition must occur. This transition, which frees nuclides from the waste form, is the result of dry oxidation or aqueous alteration of the waste form. Both are temperature-dependent processes that occur only after container and cladding breach.

The dry oxidation process goes forward whenever the fule matrix is exposed to oxygen (i.e., for rods with failed cladding in failed containers). The alteration process only goes forward when failed rods are exposed to water. Under this version, each unit of the fuel matrix can be either oxidized or altered, but not both.

Both the dry oxidation and aqueous aiteration processes alter the waste form so that highly soluble nuclides (i.e., alteration rate limited) can be released. For each period, the model determines the amount of material in fuel rods with failed cladding that has not been oxidized or altered. It then computes the amount that is oxidized during the period. This value is subtracted from the total amount that was unoxidized and unaltered at the beginning of the period. Then the alteration model is applied to the remaining unoxidized and unaltered material. Thus oxidation is assumed to take precedence over aqueous alteration.

Dry Oxidation of the Waste Form. Once a container has failed, the fuel matrix will be exposed to atmospheric oxygen. The $\mathrm{UO}_{2}$ in those fuel rods with failed cladding will begin to oxidize to $\mathrm{U}_{3} \mathrm{O}_{8}$. In general, the rate of oxidation depends on the temperature of the fuel matrix, the exposed surface area of the fuel matrix, and the availability of oxygen. In this ve:sion of YMIM, a simpler approach is taken. It is conservatively assumed that there is sufficient oxygen and exposed fuel matrix surface area to allow the waste form to oxidize as quickly as oxygen can penetrate. Thus, the oxidation rate is only a function of temperature. The rate at which oxidation will penetrate the fuel pellets has an Arrhenius relationship with temperature. Therefore, it is assumed here that the rate at which the fuel matrix oxidizes has an Arrhenius relationship with temperature.

Under this simple model, the time required to completely oxidize a the fuel matrix decreases as the temperature increases. Conversely, the fraction of the fuel matrix that is oxidized per year increases as the temperature increases. To specify the relationship, the user specifies the time required to completely oxidize the fuel matrix at two different temperatures. The inverse of the time required at a temperature is the fraction of the fuel matrix that is oxidized per year at that temperature. Using these two oxidation times, an Arrhenius equation is fitted to calculate the fraction of the fuel matrix that is oxidized per year as a function of temperature. The equation for the fraction oxidized is of the form:

$$
F_{\text {oxid }}(T)=k_{1} \cdot \exp \left(\frac{-k_{2}}{T}\right)
$$

where

$$
\begin{aligned}
T & =\text { absolute temperature }(\mathrm{K}), \\
k_{1}, k_{2} & =\text { fitted constants. }
\end{aligned}
$$


The fraction calculated using this equation is the fraction of the original mass of fuel in a fuel rod, not the fraction of the remaining unoxidized material in the fuel rod. Thus, the mass of material oxidized in a period is $F_{\text {oxid }}$ times the initial mass of the fuel in a fuel rod.

The oxidation model is applied each period to compute the additional amount of the fuel matrix that is oxidized. Each period, the number of rods with failed cladding and their temperature are known. Using Eq. (3-26), the additional fraction of the fuel matrix oxidized per year is computed. This fraction is multiplied by the total number of rods with failed cladding and which have not yet completely oxidized (discussed below) to obtain the total mass of the fuel matrix that is oxidized. This mass is in terms of fraction of a fuel mass in a single rod.

The calculation of the amount of the fuel matrix oxidizing in each period must take into account fuel rods whose fuel matrix has already completely oxidized. If the fraction of the fuel matrix that oxidizes each period were simply multiplied by the number of rods wuth failed cladding, the total amount of oxidized material would be overestimated since the model would eventually add new oxidized material from fuel rods whose fuel matrix had already completely oxidized. To account for this, the number of rods whose claddining fail in each period is stored. In each subsequent period, the fraction oxidized is computed and subtracted from the total mass of rods whose cladding has failed and have not yet oxidized. The mass oxidized in the current period is subtracted from the state 'fáiled mass' and added to the state 'oxidized mass' in the accounting structure.

Aqueous Alteration of the Waste Form. Waste form alteration is an aqueous process that is dependent on temperature, carbonate concentration, and $\mathrm{pH}$. Alteration of the $\mathrm{UO}_{2}$ matrix follows the function (Gray at al., 1992):

Rate $=A \cdot 10^{(B+C \cdot \log (\text { carbonate conc })+D \cdot(-\mathrm{pH})-E / \text { temp })}$

The parameters for this function $(A, B, C, D, E)$ are input to the Dissolution and Accounting module in a file read by the initialization routine. The alteration rate is given in units of grams of $\mathrm{UO}_{2}$ per square meter of exposed waste form surface per year $\left(\mathrm{g} / \mathrm{m}^{2} \cdot \mathrm{yr}\right)$. The total amount of the $\mathrm{UO}_{2}$ matrix altered during the current interval is therefore the alteration rate multiplied by the length of the current period during which the fuel rods are exposed to water, multiplied by the exposed surface area of all fuel rods with failed cladding in a container. The amount of each nuclide altered is this amount multiplied by the mass of that iluclide per mass $\mathrm{UO}_{2}$ in the waste form. The mass of each nuclide altered is moved from the state 'failed mass' to the state 'altered mass.'

3.10.2.5 Nuclide Release Processes. The model accounts for both gaseous and aqueous releases. Gaseous release takes place only for those nuclides specified to have a gaseous release mode and occurs when containers and fuel rods fail, independent of the presence of water. Aqueous release occurs for all nuclides and only when water is present in a failed container.

Aqueous Release Models. Three sources contribute to the mass of a nuclide available for aqueous release:

(1) Nuclides that have been freed from the waste form by aqueous alteration.

(2) Nuclides that have been freed from the waste form by air oxidation.

(3) Nuclides that have migrated to the surface of the waste form during reactor operation, and which are available for release in a pulse as soon as water encounters a fuel rod with failed cladding.

The amount of the nuclide available for transport is the mass of the nuclide that has been freed from the waste form by either aqueous alteration or air oxidation, and the amount that has migrated to the surface of the waste form and is available for immediate transport. The mass of each.nuclide made available for transport by the pulse release mechanism is defined as the pulse fraction computed by the Nuclide Behavior module multiplied by the mass of that nuclide in the fuel matrix of rods with failed cladding that have not previously released a pulse. Since only part of the waste form surface is exposed after cladding failure, only a fraction of the pulse amount defined is actually used. The actual pulse amount is the pulse amount provided by nuclide behavior multiplied by the fraction of the waste form surface that is not covered by the failed cladding. The mass of a nuclide available for aqueous transport is the sum of 'altered mass,' 'oxidized mass,' and the pulse release amount. 
The maximum amount of any nuclide that the water is capable of transporting during a time interval is the product of the solubility limit provided by the Nuclide Behavior module and the volume of water flowing over fuel matrix in rods with failed cladding during the interval. For some nuclides, however, the solubility is so high that the maximum amount that the water can carry exceeds the total amount of the nuclide that is actually available. The actual mass transported for the period is the minimum of (1) the amount available for transport, and (2) the amount that the water entering the container is capable of holding. The amount of mass released is subtracted from the state variables 'oxidized mass,' 'altered mass,' and 'failed mass.' Mass released in the pulse is subtracted from the state 'failed mass' since the pulse release mass does not need to be freed from the fuel matrix by alteration or oxidation before release. Mass releases by other aqueous and gaseous release modes are first subtracted from the state 'oxidized mass.' Any mass released in excess of the amount available in the state 'oxidized mass' is removed from the state 'altered mass.'

Gaseous Release Models. Nuclides that are specified to have a gaseous release mode, such as ${ }^{14} \mathrm{C}$, can be released from the following locations in a container:

- The oxidized outer layer of the fuel cladding.

- The "gap" between the cladding and the spent fuel.

- The spent fuel matrix.

- The Zircalloy cladding material.

- Other fuel assembly elements.

Release from the first three sources is modeled in this version of YMIM. Release from the cladding material and the other fuel assembly elements is slower and is not accounted for in this version.

Because ${ }^{14} \mathrm{C}$ is a gas, it does not depend on the presence of water for its release in the same way that the solid nuclides do. The release from the outer layer of cladding is assumed to occur when the container fails. The release from the gap between the spent fuel pellet and the cladding is assumed to occur when the container and the cladding have both failed (in general, they fail at different times, but both must fail before there is release from the container). The release from the spent fuel matrix is assumed to occur as the fuel is altered, either through aqueous alteration or dry oxidation.

The release from the outer layer of cladding is computed on the basis of a mass released per unit rod surface area specified by the user. The Dissolution and Accounting module computes the total rod surface area and the resultant release. This amount is assumed to be released in the period when the container fails. Note that this amount is not considered to be part of the ${ }^{14} \mathrm{C}$ inventory, but rather an additional amount that is created on the rod surface. Therefore, the amount of mass released by this mechanism is not subtracted from the ${ }^{14} \mathrm{C}$ inventory in the dissolution accounting structure.

The amount of the release from the cladding gap is computed just as for any other nuclide. The user specifies the fraction of the inventory that is contained in the gap. In the first period that a container fails, the total amount from all of the rods in the container that have failed up to that period is assumed to be released. In each period thereafter, the number of rods failing in each period is computed. The corresponding amount of ${ }^{14} \mathrm{C}$ contained in the gaps of the rods that failed is computed and assumed to be released in that period. Mass released from the cladding gap is subtracted from 'failed mass' in the accounting structure.

3.10.2.6 Nuclide Decay. At the end of the release calculations for the current period, the amount of each nuclide in all state variables is reduced by the amount that has undergone radioactive decay. The decay fraction is provided by the Nuclide Behavior module.

\subsubsection{Parameters, Input Variables, and Output Variables}

\section{Input Parameters}

- Number of fuel rods per container.

- Waste form oxidation temperature $1\left({ }^{\circ} \mathrm{C}\right)$.

- Time to completely oxidize waste form at temperature 1 (yr).

- Waste form oxidation temperature $2 \cdot\left({ }^{\circ} \mathrm{C}\right)$.

- Time to completely oxidize waste form at temperature 2 (yr).

- Coefficients $A, B, C, D$, and $E$ of the alteration-rate equation:

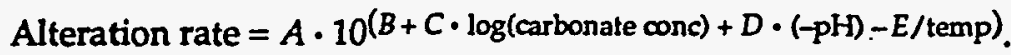


Input Variables from Other Modules

- Fraction of containers failing in the current period from Container Failure.

- Fraction of cladding failing in the container in the current period from Cladding Failure.

- Cladding temperature $\left({ }^{\circ} \mathrm{C}\right)$ from Temperature.

- Initial mass of each nuclide contained in a single fuel rod (g) from Nuclide Behavior.

- Total mass of fuel a single fuel rod (g) from Nuclide Behavior.

- Carbonate concentration (moles/liter) from Near Field Chemistry.

- $\mathrm{pH}$ from Near-Field Chemistry.

- Release mode of each nuclide ( $S$ for soluble or $G$ for gaseous) from Nuclide Behavior.

- Solubility limit of each nuclide (g/liter) from Nuclide Behavior.

- Pulse release fraction of each nuclide from Nuclide Behavior.

- Fraction of nuclide mass decaying in the current period from Nuclide Behavior.

- Exposed surface area of fuel matrix in a single fuel rod with failed cladding $\left(\mathrm{m}^{2}\right)$ from Internal Container Flow.

- Total surface area of fuel matrix in a single fuel rod with failed cladding $\left(\mathrm{m}^{2}\right)$ from Internal Container Flow.

- Wetted surface area of fuel matrix in a single fuel rod with failed cladding $\left(\mathrm{m}^{2}\right)$ from Internal Container Flow.

- Total volume of water flowing over all fuel rods with failed cladding (liters/yr) from Internal Container Flow.

- Surface area of fuel cladding of a single fuel rod $\left(\mathrm{m}^{2}\right)$ from Internal Container Flow.

- Mass of each nuclide on the surface of the cladding of a single fuel rod $\left(\mathrm{g} / \mathrm{m}^{2}\right)$ from Nuclide Behavior.

- Length of current interval (yr) from Time Points.

\section{Output Variables}

- Mass of each nuclide released during the current interval (g/yr).

- Mass of each nuclide altered during the period ( $\mathrm{g} / \mathrm{yr}$ ).

- Mass of each nuclide oxidized during the period ( $\mathrm{g} / \mathrm{yr}$ ).

- Time history of container failures (fraction/yr).

- Time history of cladding failures (fraction/yr).

\section{Input File Formats}

In order to construct a scenario for YMIM, the following data is needed:

- Temperature time history for fuel rods and the container wall.

- Hydrology time history.

- Near-field chemistry time history.

It is the user's responsibility to ensure that the above scenarios are consistent with each other. For example, the time when water returns should be greater than or equal to the time at which the container temperature drops below boiling.

Ten text input files contain the above information as well as the physical parameters necessary to run YMIM Version 2.1. They may be Excel text files, Microsoft Word documents, or any text format file. The file names are:

(1)

time_points.txt near_field_hydrology.txt near_field_chemistry.txt rock_to_container_flow.txt nuclide_behavior.txt temperature.txt container_failure.txt internal_container_flow.txt 
(9) cladding_failure.txt

(10) dissolution_and_accounting.txt

Each of the modules requires a given set of inputs and parameters. Inputs are supplied to the modules from either one of the above text files or from another module.

The ten input files that define parameters for the various modules have the following format. Lines that contain data are preceded by the character $D$, while all other lines are preceded by a $C$. Comment lines may be inserted at any point in the input file. Any text included in a data line must appear in the data file exactly as it appears in the sample files. The modules look for these items in order to ensure that the parameters are being read into the correct variables. Data entries are separated by spaces or tabs. Any number of spaces or tabs between data entries are admissible.

\section{1 time_points.txt}

Time Points is the file that contains the end time for each period over which the model will be evaluated. The Time Points file must be in the following format:
D \# of time points $=6$
C
D 25
D 50
D 100
D 500
D 1000
D 10000

This example file indicates that the first period of interest runs from 0 to $25 \mathrm{yr}$, the second from 25 to $50 \mathrm{yr}$, etc.

The maximum number of time points that the model can handle is 25 . To ensure good results, the time grid should be defined in such a way that the intervals are finer when the temperature is high and changing quickly.

\section{2 near_field_hydrology.txt}

The hydrology file contains data on the flux history of the repository and is in the following format:
D \# of periods $=5$
C
C endpoints: year
C flux: $\mathrm{mm} / \mathrm{yr}$
C duration: years
C frequency: number per year
C
C end points
D
10000
20000
50000
1000000
C matrix flux
D 0.0
0.0
5.0
5.0
5.0
C matrix flux episode duration
D $\quad 0.10$
0.10
0.10
0.10
0.10
C
C matrix flux episode frequency 


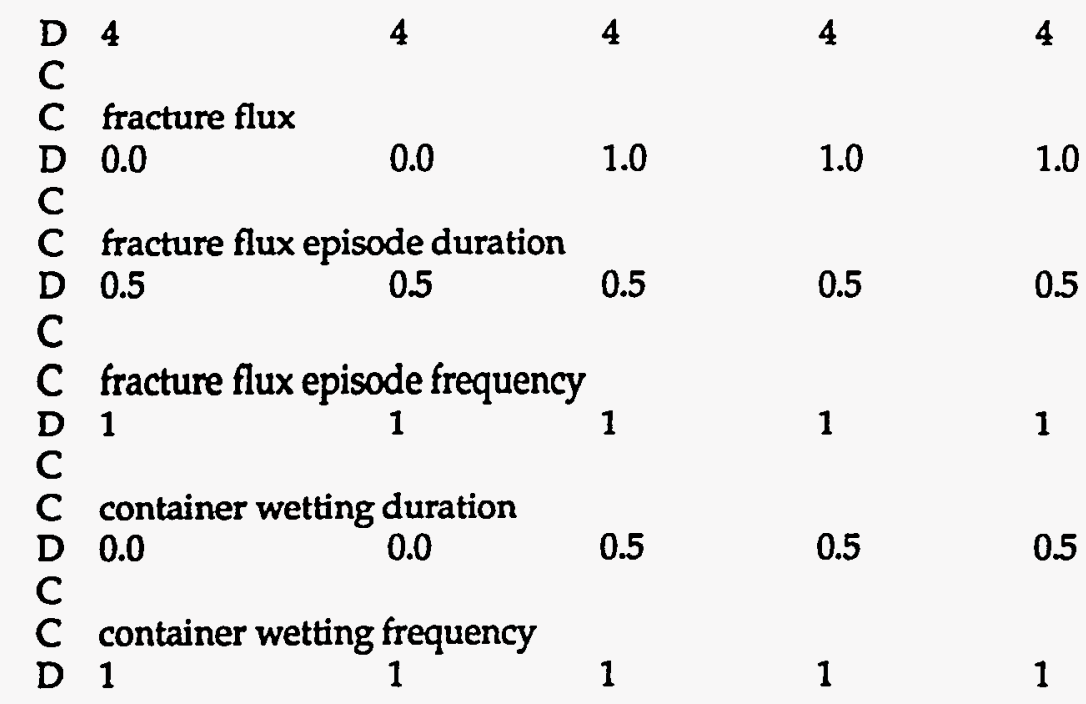

Note: conditions at time zero must be specified.

The values of flux, duration, and frequency are interpolated between data points and used as constants outside the defined range. This example shows a matrix flux of $0.0 \mathrm{~mm} / \mathrm{yr}$ from year 0 to 10,000 , ramping linearly to $5.0 \mathrm{~mm} / \mathrm{yr}$ at $20,000 \mathrm{yr}$, and holding at $5.0 \mathrm{~mm} / \mathrm{yr}$ for the rest of the scenario. In addition, matrix flux episodes occur four times per year, each lasting $0.1 \mathrm{yr}$.

\section{3 near_field_chemistry.txt}

This file contains the time history of water chemistry at the site. Its format is as follows:
D \# of periods $=2$
C
$D$ endTime $\mathrm{pH}$
D $0 \quad 8$
D $100000 \quad 8$

$\begin{array}{llll}\text { eH } & \text { chlorine } & \text { carbonate } & \text { fluorine } \\ 5 & 37 & 0.007 & 300 \\ 5 & 37 & 0.007 & 300\end{array}$

Note: conditions at time zero must be specified.

This example indicates water with a pH of 8, eH of 5 , chlorine concentration of $37 \mathrm{ppm}$, carbonate concentration of 0.007 moles/liter, and fluorine concentration of $300 \mathrm{ppm}$, from 0 to 100,000 yr.

\section{4 rock_to_container_flow.txt}

This file contains the parameters that define water flow conditions from the rock wall to the waste container. Its format is as follows:

D fracture flow collection area $\left(m^{\wedge} 2\right)=0.38$

D matrix flow collection area $\left(\mathrm{m}^{\wedge} 2\right)=0.0$

\section{5 nuclide_behavior.txt}

Nuclide Behavior contains data on the nuclides present in an individual rod and is in the following format:

D number of nuclides present $=5$ 


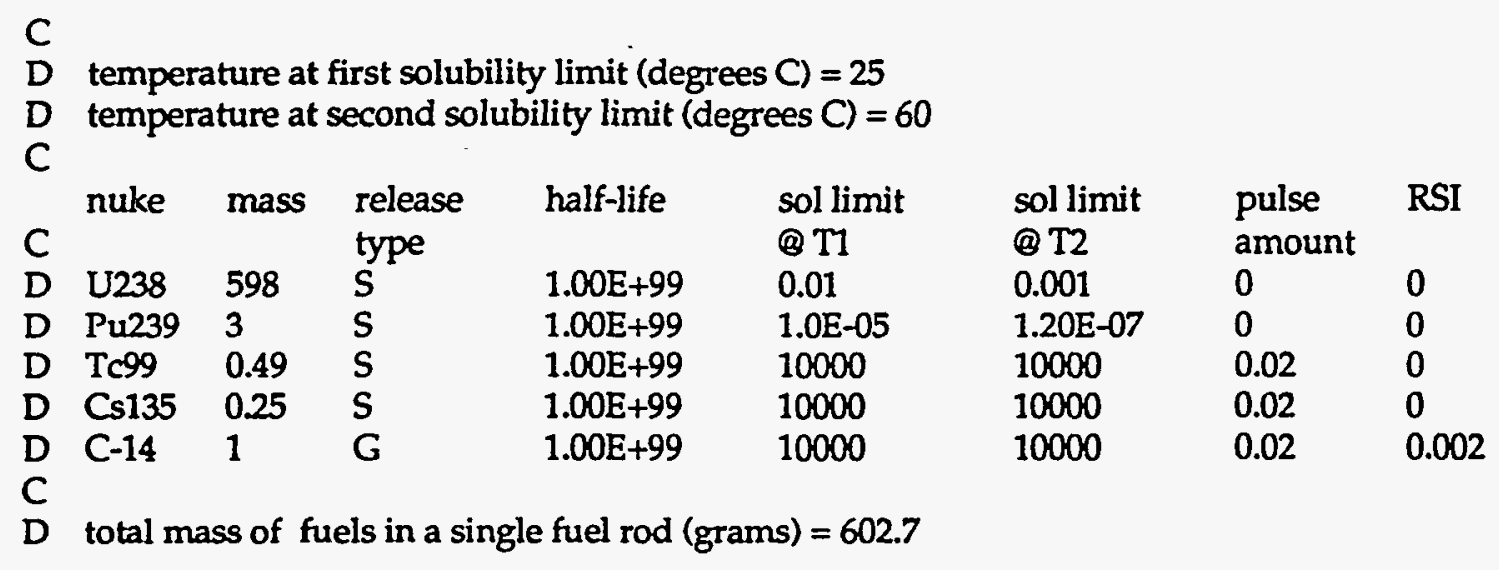

\section{6 temperature.txt}

This file contains the temperature data for each period. The temperature format is as follows:

$\begin{array}{lll}\mathrm{D} \text { \# of periods =5 } & & \\ \mathrm{C} & \begin{array}{l}\text { rod temp } \\ \text { (degrees C) }\end{array} & \begin{array}{l}\text { container temp } \\ \text { (degrees C) }\end{array} \\ \text { C end time } & & \\ \text { C (year) } & 410 & 310 \\ \text { D } 0 & 400 & 300 \\ \text { D } 25 & 350 & 270 \\ \text { D } 50 & 275 & 220 \\ \text { D } 100 & 10 & 90 \\ \text { D } 10000 & & \end{array}$

Note: conditions at time zero must be specified.

The temperature values are interpolated between data points and used as constants outside the defined range. This example indicates a container temperature of $310^{\circ} \mathrm{C}$ beginning at year 0 , ramping down linearly to $300^{\circ} \mathrm{C}$ at $25 \mathrm{yr}$, etc.

\section{7 container_failure.txt}

This file contains the parameters used by the container failure module. It includes corrosion rate data as well as parameters for failure types other than corrosion. The format for this file is as follows:
D containers failing by defect (fraction) $=0.00$
D containers failing by mechanical (fraction) $=1.0$
$D$ beginning time for mechanical failure distribution (years) $=0.0$
D ending time for mechanical failure distribution (years) $=1.0$
D parameter for exponential defective failure distribution $=0.01$
C
D number of pits on container surface $=500$
D number of container walls $=2$
C
C WALL 1 (outer wall)
C
D wall thickness $=10.0$
C 
dry oxidation active: $Y$

D oxidation temperature $1($ degrees $C)=50$

D oxidation rate at $\mathrm{T} 1=0.00005$

D oxidation temperature $2($ degrees $C)=100$

D oxidation rate at $\mathrm{T} 2=0.00025$

C

D general aqueous corrosion active: $Y$

$D$ general corrosion rate at 20 degrees $C=0.012$

D peak general corrosion rate occurs at temperature (degrees $C$ ) $=80$

D general corrosion rate at peak temperature $=0.038$

D pitting factor $=1$

C

D localized aqueous corrosion active: $N$

D localized corrosion temperature 1 (degrees $\mathrm{C}$ ) $=50$

D incremental growth at $\mathrm{T} 1=.000001$

D expected number of growths/year at $\mathrm{T} 1=50$

D localized corrosion temperature 2 (degrees $C$ ) $=100$

D incremental growth at T2 $=.000002$

D expected number of growths/year at $\mathrm{T} 2=50$

C

C

C

C WALL 2 (inner wall)

C

D wall thickness $=4.0$

C

D dry oxidation active: $\mathrm{N}$

D oxidation temperature 1 (degrees $C)=50$

D oxidation rate at $\mathrm{T} 1=0.00001$

D oxidation temperature 2 (degrees $C$ ) $=100$

D oxidation rate at $\mathrm{T} 2=0.000001$

C

D general aqueous corrosion active: $N$

D general corrosion rate at 20 degrees $C=0.00$

D peak general corrosion rate occurs at temperature (degrees $C$ ) $=80$

D general corrosion rate at peak temperature $=0.00$

D pitting factor $=1$

C

D localized aqueous corrosion active: $Y$

D localized corrosion temperature 1 (degrees $C$ ) $=70$

$D$ incremental growth at $\mathrm{T} 1=0.03$

D expected number of growths/year at $\mathrm{T} 1=0.033$

D localized corrosion temperature 2 (degrees $C$ ) $=100$

D incremental growth at $\mathrm{T} 2=2.994$

D expected number of growths/year at T2 $=0.033$

\section{8 internal_container_flow.txt}

This file contains the parameter information for the Internal Container Flow module, and includes information about the physical state of a fuel rod before and after oxidation. Its format is as follows:

D volumetric expansion of waste form due to oxidation $=0.33$

D initial cross sectional area of a fuel pellet $\left(\mathrm{m}^{\wedge} 2\right)=0.00009369$ 
D length of fuel rod $(m)=3.602$

\section{9 cladding_failure.txt}

This file contains data on the failure distributions of rods due to the three failure modes. Its format is as follows:
C creep \%
creep
C period
D 0.2
300
hydride \%
hydride period
fluorine
period
C
D lower limit for creep cladding failure (degrees $C$ ) $=350$
D lower limit for hydride cladding failure (degrees $\mathrm{C}$ ) $=100$
D minimum fluorine concentration for fluorine cladding failure $(\mathrm{ppm})=\mathbf{2 0 0 . 0}$

This file indicates that $20 \%$ of the rods would fail by creep over a period of $300 \mathrm{yr}, 50 \%$ of the rods would fail by hydride precipitation over a period of $500 \mathrm{yr}$, and all rods not failing by creep or hydride precipitation would fail over a period of $5000 \mathrm{yr}$ if exposed to fluorine above $200 \mathrm{ppm}$.

\subsection{0 dissolution_and_accounting.txt}

This file contains the parameter information for the Dissolution and Accounting module. It contains parameters about the fuel rods as well as parameters for the alteration rate equation. Its format is as follows:

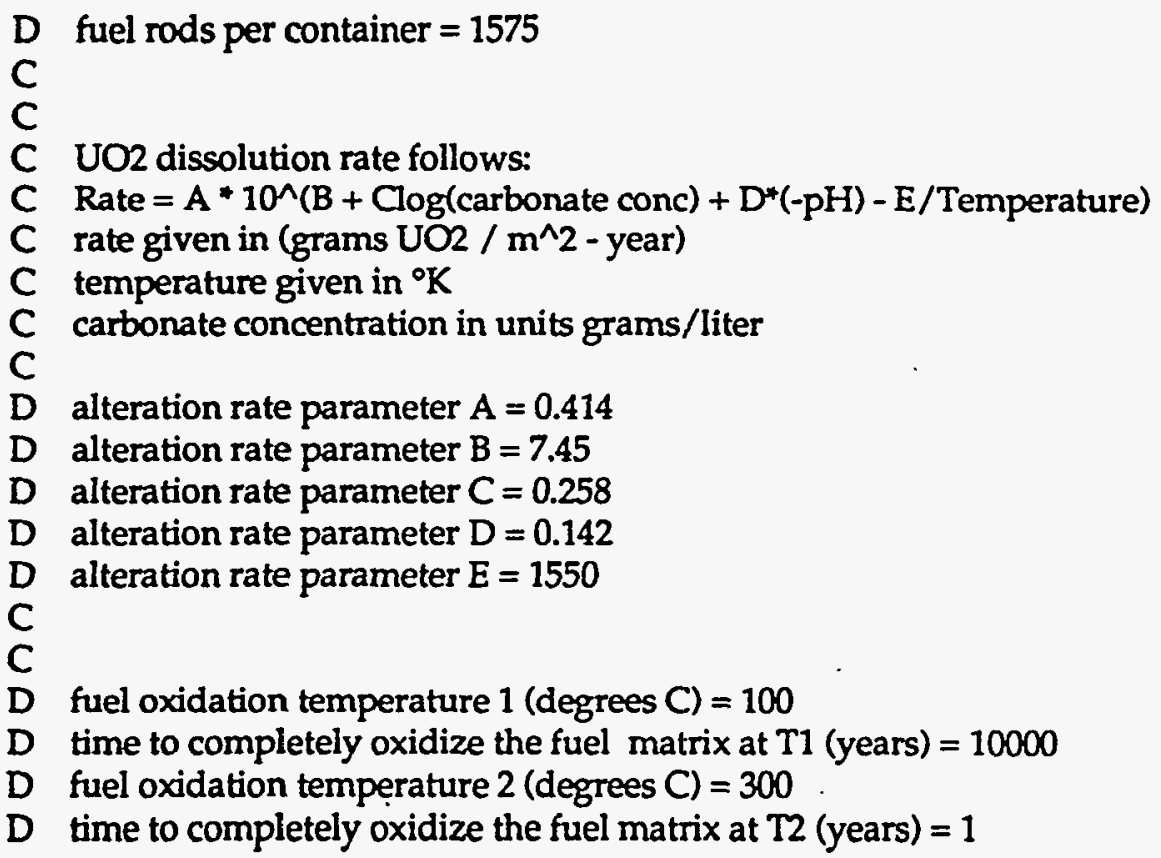

\section{Running YMIM}

With the ten input files listed above in the same folder as the YMIM application, YMIM may be launched by double clicking on the application icon. While running, YMIM displays the number of the 
current calculation period along with the total number of calculation periods. When finished, YMIM . writes the results of the run to the Mass Transfer file.

\section{Format of Output File}

The output is printed to the file Mass_Transfer.txt.' Table 6-1 shows an example output file. The output to this file includes information about mass of each nuclide released, container and cladding failures, and fuel matrix alteration and oxidation rates. The output file is in tab delimited form so that the data in the output file can be graphed by programs such as Excel. The output variables and their units are:

- Date and time output file was created

- Version of each module used to compute releases.

- End times of analysis periods (yr).

- Release for each nuclide (grams/container-year).

- Container failures (fraction/year).

- Cladding failures (percent failed/container-year).

- Amount of each nuclide altered (grams/container-year).

- Amount of each nuclide oxidized (grams/container-year). 
output file created: 09/14/94 15:57:58

\begin{tabular}{|c|c|c|c|c|}
\hline$* *$ & Near Field Hydrology: & version@(\#)nearFieldHydrology.cc & $1.16 / 30 / 931$ & $* *$ \\
\hline$* *$ & Near Field Chemistry: & version@(\#)nearFieldChemistry.cc & $1.16 / 30 / 931$ & ** \\
\hline ** & Rock to Container Flow: & version@(\#)rockToContainerFlow.cc & $1.57 / 16 / 931$ & $* *$ \\
\hline$*$ & Dissolution Accounting: & version@(\#)Dissolution.cc & $2.109 / 29 / 931$ & \# \\
\hline$* *$ & Internal Container Flow: & version@(\#)intemalContainerFlow.cc & $1.49 / 1 / 931$ & $* *$ \\
\hline ** & Time Points: & version@(\#)timePoints.cc & $1.16 / 30 / 931$ & $* *$ \\
\hline ** & Nuclide Behavior: & version@(\#)nuclideBehavior.cc & $1.39 / 11 / 931$ & ** \\
\hline 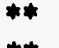 & Temperature: & version@(\#)temperature.cc & $1.16 / 30 / 931$ & *** \\
\hline
\end{tabular}

Mass Transfer of Nuclides (grams released/container-year)

end year of period 10

U238

Pu239

Cs135

w

C-14
Container and Rod Failure

end year of period

container failure (fraction failed/year)

rod failure (fraction failed/year)

mass altered (grams altered/container-year)

U238
Pu239
Cs135
C-14

mass oxidized (grams oxidized/container-year)

$\mathrm{U} 238$

Pu239

Cs135

C-14
10

$0.00 \mathrm{E}+00$

$0.00 \mathrm{E}+00$

7.21E-02

10

$1.90 \mathrm{E}-04$

$5.00 \mathrm{E}-02$

$0.00 \mathrm{E}+00$

$0.00 \mathrm{E}+00$

$0.00 \mathrm{E}+00$

$0.00 \mathrm{E}+00$

1.79E+00

$8.99 \mathrm{E}-03$

7.49 E- 04

2.91E-03
100

2.06E-07

$0.00 \mathrm{E}+00$

1.71E-02

6.60E-02

100

$1.19 \mathrm{E}-04$

$1.00 \mathrm{E}-01$

$0.00 \mathrm{E}+00$

$0.00 \mathrm{E}+00$

$0.00 \mathrm{E}+00$

$0.00 \mathrm{E}+00$

$9.06 \mathrm{E}+00$

4.54E-02

3.79E-03

1.47E-02
500

1.35E-04

$0.00 \mathrm{E}+00$

$1.68 \mathrm{E}-02$

$2.49 \mathrm{E}-02$

500

1.81E-05

$3.00 \mathrm{E}-01$

$0.00 \mathrm{E}+00$

$0.00 \mathrm{E}+00$

$0.00 \mathrm{E}+00$

$0.00 \mathrm{E}+00$

$1.99 \mathrm{E}+01$

9.95E-02

8.32E-03

$3.23 \mathrm{E}-02$
1000

1.98E-04

$0.00 \mathrm{E}+00$

1.12E-02

$1.74 \mathrm{E}-10$

1000

2.68E-07

$0.00 \mathrm{E}+00$

1500

$1.80 \mathrm{E}-09$

$0.00 \mathrm{E}+00$

$0.00 \mathrm{E}+00$

$0.00 \mathrm{E}+00$

$0.00 \mathrm{E}+00$

$0.00 \mathrm{E}+00$

$0.00 \mathrm{E}+00$

$0.00 \mathrm{E}+00$

$0.00 \mathrm{E}+00$

$0.00 \mathrm{E}+00$

$3.51 \mathrm{E}+00$

1.74E-02

$1.47 \mathrm{E}-03$

5.67E-03
9.52E-04

4.64E-06

3.98E-07

1.53E-06
2000

8.23E-04

5.62E-07

$0.00 \mathrm{E}+00$

$0.00 \mathrm{E}+00$

\section{0}

$1.22 \mathrm{E}-11$

$0.00 \mathrm{E}+00$

$0.00 \mathrm{E}+00$

$0.00 \mathrm{E}+00$

$0.00 \mathrm{E}+00$

$0.00 \mathrm{E}+00$

2.76E-06

$1.32 \mathrm{E}-08$

1.15E-09

4.56E-09

Table 6-1. Example output file for YMIM Version 2.1. 


\section{References}

Abramowitz, M., and I. A. Stegun (1964), Handbook of Mathematical Functions with Formulas, Graphs, and Mathematical Tables, p. 933, U.S. Government Printing Office, Washington, DC (NNA.890713.0197).

Henshall, G. A., W. G. Halsey, W. L. Clarke, and R. D. McCright (1993), Modeling Pitting Corrosion Damage of High Leoel Radioactive Waste Containers, with Emphasis on the Stochastic Approach, Lawrence Livermore National Laboratory, Livermore, CA, UCRL-ID-111624 (NNA.921222.0001).

Gray, W. J., H. R. Leider, and S. A. Steward (1992), Parametric Study of LWR Spent-Fuel Dissolution Kinetics, Lawrence Livermore National Laboratory, Livermore, CA, UCRL-JC-110160 (NNA.920710.0109).

Gumbel, E. J. (1954), Statistical Theory of Extreme Values and Some Practical Applications, pp. 19-21, National Bureau of Standards Applied Mathematics Series 33 (NNA.921215.0085). 
The following number is for Office of Civilian Radioactive Waste Management Records Management purposes only and should not be used when ordering this document:

Accession Number: $\quad$ MOL.19950419.0110 